\title{
PROVENIÊNCIA DAS ROCHAS METASSEDIMENTARES DO GRUPO ARAXÁ NA PORÇÃO CENTRAL DA FAIXA BRASÍLIA
}

\author{
PROVENANCE OF METASEDIMENTARY ROCKS OF THE ARAXÁ GROUP IN THE CENTRAL \\ BRASÍLIA BELT
}

\section{Guillermo Rafael Beltran NAVARRO ${ }^{1}$, Antenor ZANARDO ${ }^{1}$, Cibele Carolina MONTIBELLER ${ }^{2}$, Thaís Güitzlaf LEME $^{2}$, Fabiano Tomazini da CONCEIÇÃ ${ }^{3}$, Claudio de Morisson VALERIANO ${ }^{4}$} \author{
Rio Claro. E-mails: guillermo.navarro@unesp.br; antenor.zanardo@unesp.br \\ Paulista, Campus de Rio Claro. E-mail: fabiano.tomazini@unesp.br \\ de Janeiro. E-mail: valeriano.claudio@gmail.com

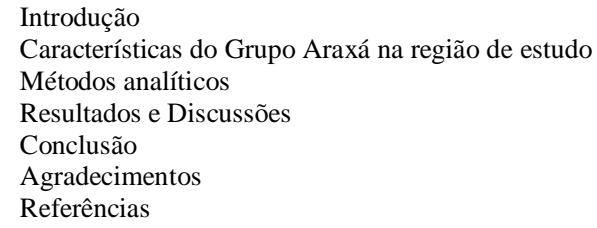

${ }^{1}$ Instituto de Geociências e Ciências Exatas, Departamento de Petrologia e Metalogenia, Universidade Estadual Paulista, Campus de

${ }^{2}$ Pós-Graduação em Geociências e Meio Ambiente, Instituto de Geociências e Ciências Exatas, Departamento de Petrologia e Metalogenia, Universidade Estadual Paulista, Campus de Rio Claro. E-mail: cibele.cm@ outlook.com, thais.guitzlaf@hotmail.com ${ }^{3}$ Instituto de Geociências e Ciências Exatas, Departamento de Planejamento Territorial e Geoprocessamento, Universidade Estadual

${ }^{4}$ Faculdade de Geologia, Departamento de Geologia Regional e Geotectônica, Universidade do Estado do Rio de Janeiro (UERJ), Rio

RESUMO - O Grupo Araxá na região de Morrinhos - Marcelândia é constituído por rochas pelíticas e psamo-pelíticas metamorfisadas em fácies anfibolito, no campo de estabilidade da cianita/estaurolita. A composição química e as razões $\mathrm{La} / \mathrm{Lu}, \mathrm{La} / \mathrm{Sc}, \mathrm{Th} / \mathrm{Sc}, \mathrm{La} / \mathrm{Co}$, $\mathrm{Th} / \mathrm{Co}$ e $\mathrm{Cr} / \mathrm{Th}$ destas rochas sugerem que a principal fonte destes sedimentos são rochas ígneas félsicas formadas em arcos magmáticos . As idades $\mathrm{T}_{\mathrm{DM}} \mathrm{Nd}(1,21$ e $1,76 \mathrm{Ga})$ e as idades $\mathrm{U} / \mathrm{Pb}(<1,0 \mathrm{Ga}$ e $>1,0 \mathrm{Ga}$ em cristais de zircão detrítico) sugerem contribuição de uma fonte neoproterozoica (predominante) e uma contribuição de outra fonte mais antiga paleo-mesoproterozoica. A congruência dos dados geocronológicos com as assinaturas geoquímicas desta unidade permite afirmar que grande parte do Grupo Araxá na região tem como fonte rochas formadas em arcos magmáticos neoproterozoicos, e sugerem que estes foram depositados em bacias tipo fore arc. Palavras chave: Idades modelo $\mathrm{T}_{\mathrm{DMN}} \mathrm{N}$, Geocronologia U-Pb em cristais de zircão detríticos, Geoquímica, Faixa Brasília, Província Tocantins.

ABSTRACT - The Araxá Group in the region of Morrinhos - Marcelândia is constituted of pelitic to psammo-pelitic rocks metamorphosed in amphibolite facies, kyanite/ staurolite stability field. Chemical composition and $\mathrm{La} / \mathrm{Lu}, \mathrm{La} / \mathrm{Sc}, \mathrm{Th} / \mathrm{Sc}, \mathrm{La} / \mathrm{Co}, \mathrm{Th} / \mathrm{Co}$ and $\mathrm{Cr} / \mathrm{Th}$ rates of these rocks suggest that the main source of these sediments were felsic rocks from magmatic arcs. $\mathrm{T}_{\mathrm{DMNd}} \mathrm{model}$ ages $(1.21$ and $1.76 \mathrm{Ga})$ and $\mathrm{U} / \mathrm{Pb}$ ages $(<1.0 \mathrm{Ga}$ and $>1.0 \mathrm{Ga}$ in detrital zircon) suggest contribution of a neoproterozoic (predominant) source and contributions of an older paleo-mesoproterozoic source. The congruence of these geochronological data with geochemical signatures of this geological unity allow to state that a significant part of the Araxá Group in this region had rocks from neoproterozoic magmatic arcs as source, implying that these were deposited in fore arc basins.

Keywords: TDMNd model ages, U-Pb detrital zircon geochronology, Geochemistry, Brasília Belt, Tocantins Province.

\section{INTRODUÇÃO}

O Grupo Araxá (Barbosa, 1955) corresponde a uma unidade metassedimentar localizada na Zona Interna da Faixa Brasília (Fuck, 1990), que se estende por cerca de $700 \mathrm{~km}$ na direção NWSE, desde o S-SW de Minas Gerais até o NW de Goiás (Figura 1). O Grupo Araxá foi definido, na região de Araxá-MG, sob a denominação de Formação Araxá (Barbosa, 1955). Barbosa et al. (1969) levam a denominação "Grupo Araxá" para o norte do estado de Goiás (regiões de Canabrava, Niquelândia, Peixe, Uruaçu, São Miguel do Araguaia, Amaralina e Araguaçu). Posterior-mente Barbosa et al. (1970a) estendem o Grupo Araxá para a porção sudeste do estado de Goiás (Folha Catalão) e Barbosa et al. (1970b) para a porção centro-sul do estado de Goiás (Folhas Anápolis, Morrinhos, Ipameri, Pirenópolis, Luziânia e Campo Alegre de Goiás). Embora ocorram variações no empilhamento tectono-estratigráfico, o Grupo Araxá ao longo de sua extensão é constituído dominantemente por rochas metassedimentares psamíticas (quartzitos, quartzitos micáceos) e pelíticas (calci-xistos, muscovita-quartzo xisto, muscovita-clorita xisto, biotita-granada xisto, estaurolita xisto e xistos feldspáticos), localmente com lentes de gnaisse anfibolito, anfibolito, metaultramáfica e retroeclogito (Fuck \& Marini, 1981). 


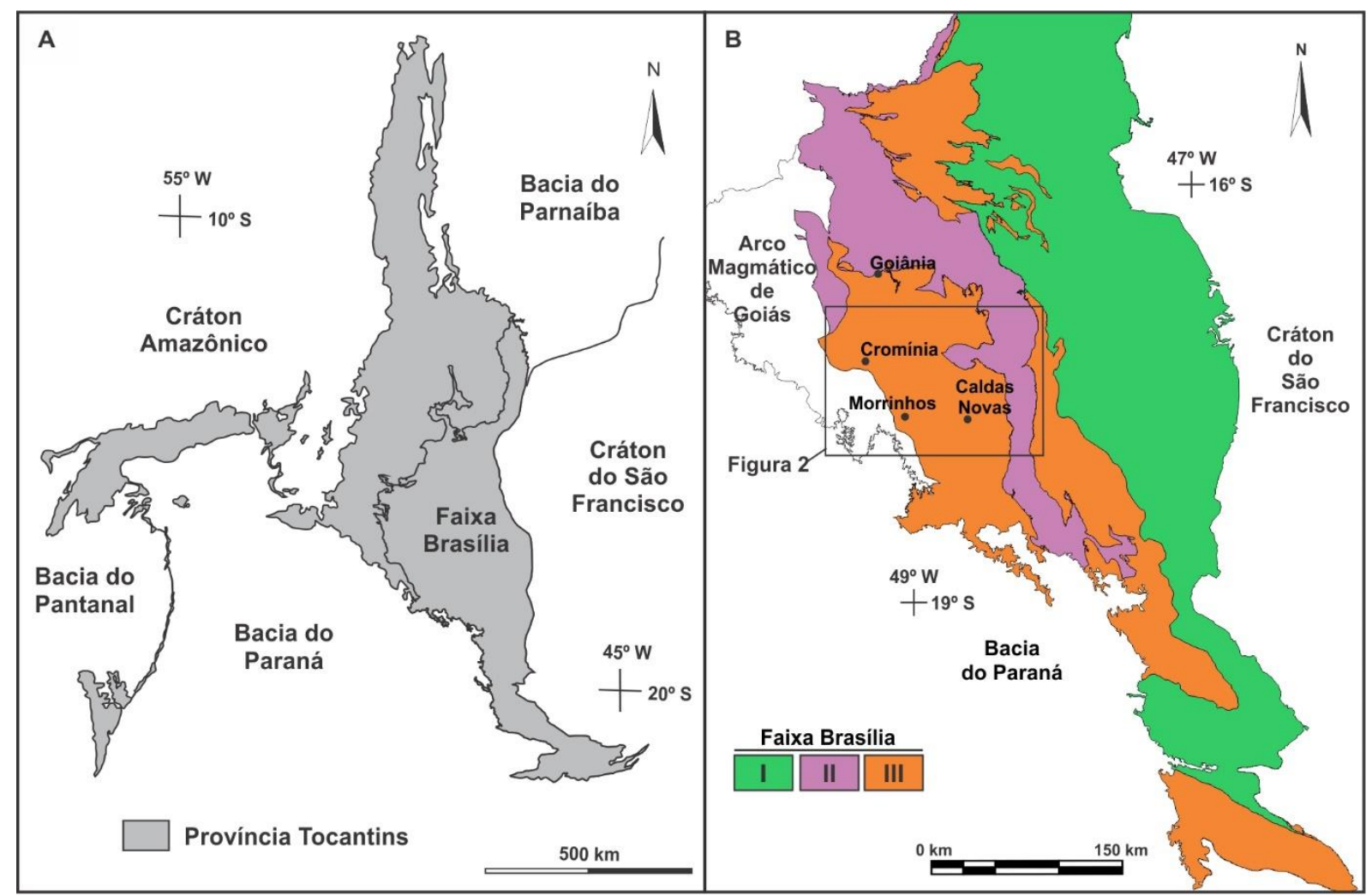

Figura 1. Mapa esquemático da Província Tocantins e da Faixa Brasília. Zona Externa: I - Grupos Paranoá, Canastra e Formações Vazante, Ibiá e porções de seu embasamento. Zona Interna: II - Granulitos e rochas associadas (Complexo Granulítico Anápolis-Itauçu e Associação Ortognáissica Migmatítica), rochas metavulcanossedimentares e granitoides associados. III - Grupo Araxá e granitoides associados. (mod. de Fuck, 1990; Hasui, 2012).

Na porção SE do Estado de Goiás, o Grupo Araxá ocorre em dois pacotes dominados por xistos, colocados tectonicamente abaixo e acima do Complexo Anápolis-Itauçu e da Associação Ortognáissica Migmatítica (Figura 2). O Grupo Araxá no pacote inferior (Unidade A) é constituído por rochas metassedimentares pelíticas, psamo-pelíticas e psamíticas (muscovita-clorita xisto, biotita-muscovita-quartzo xisto, granada-muscovita-clorita xisto, cloritaquartzo xisto, sericita quartzito, hematita xisto, hematita-sericita xisto, hematita-sericita quartzito) depositadas em ambiente plataformal (marinho raso) metamorfisadas em fácies xisto verde alto (Unidade A de Lacerda Filho et al., 1999; Moreira et al., 2008). Sequências metavulcanossedimentares (na região de Ipameri - Catalão: sequência Rio Veríssimo) e grande quantidade de corpos intrusivos graníticos (granitos tipo Ipameri: Encruzilhada, Sesmaria e Tambú) ocorrem associados ao Grupo Araxá no pacote inferior.

$\mathrm{Na}$ base do pacote superior, aflora a sequência metavulcanossedimentar Maratá, rochas metassedimentares relacionadas com a Unidade A e corpo granítico tipo Ipameri (Granito Cachoeira do Maratá, Moreira et al., 2008). A Unidade A da porção inferior do pacote superior é semelhante ao observado no pacote inferior, entretanto a ocorrência de rochas metassedimentares psamíticas é maior (quartzito, sericita quartzito).

Sobre a Unidade A ocorrem rochas metassedimentares pelíticas, psamo-pelíticas e psamíticas (calci-clorita-biotita xisto, calci-cloritabiotita xisto feldspático, granada-clorita xisto, hornblenda-granada xisto feldspático, grafita xisto e lentes de metacalcário e quartzito) depositadas em ambiente marinho metamorfisadas em fácies anfibolito (Unidade B de Lacerda Filho et al., 1999; Moreira et al., 2008).

Lentes de rochas metamáficas (anfibolito, granada anfibolito, anfibólio xisto) e metaultramáficas (serpentinito, actinolita xisto, clorita xisto e talco xisto, localmente com lentes de cromita podiforme associadas) ocorrem em ambas unidades do Grupo Araxá na região. Estas ocorrências são interpretadas como restos de assoalho oceânico, assumindo características de mélange ofiolítica (Drake Jr., 1980; Nilson, 1984; Brod et al., 1991; Strieder \& Nilson, 1992; Zanardo et al., 1996; Dardenne, 2000; Valeriano et al., 2004), obductada por cima de uma margem continental por meio de nappes, com movimento do topo de W para E (Valeriano et al., 2004). 


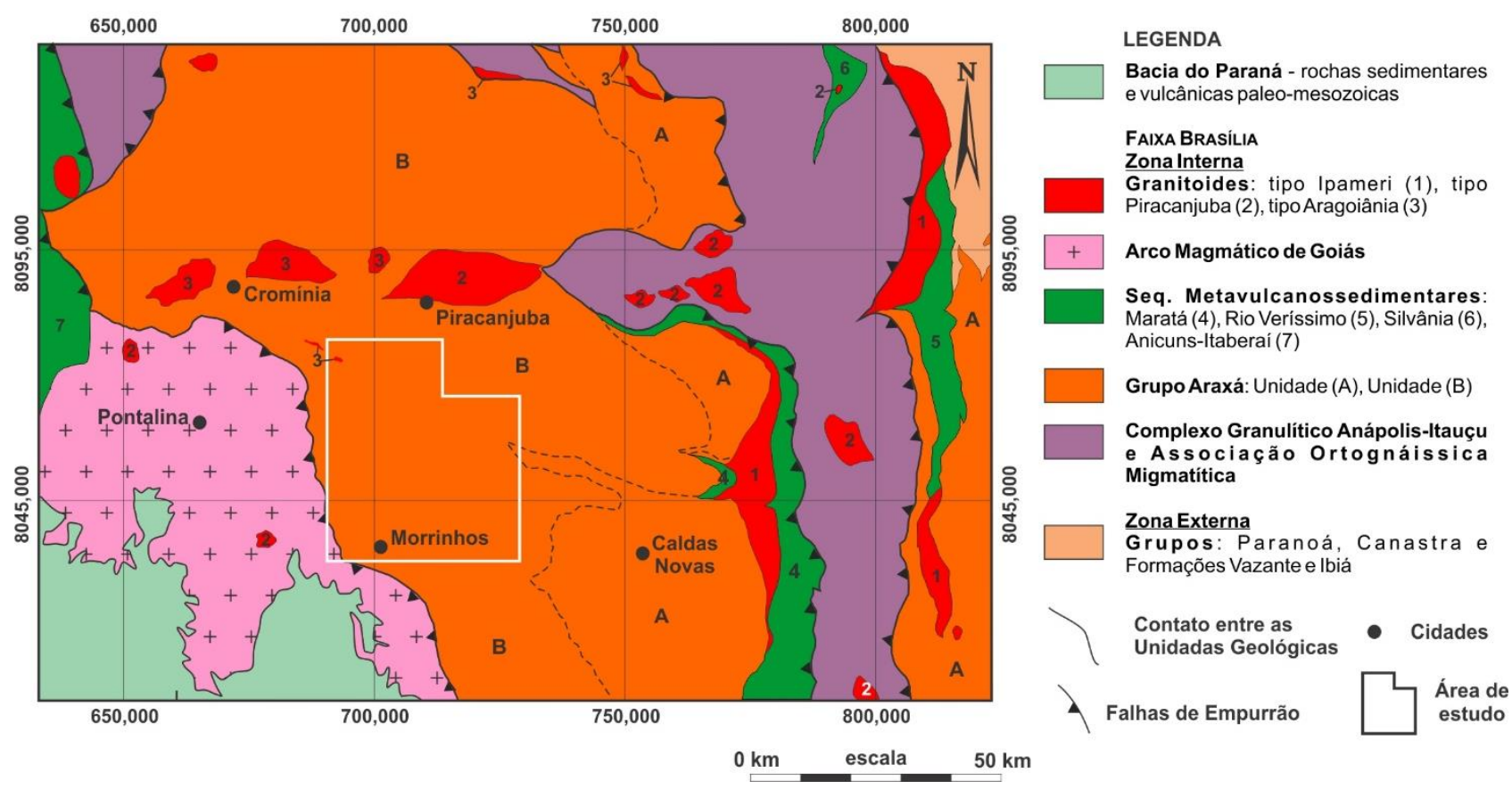

Figura 2. Mapa geológico regional (esquemático) da área de estudo (mod. de Moreira et al., 2008).

Idades modelo $\mathrm{T}_{\mathrm{DMNd}} \mathrm{de}$ rochas metassedimentares do Grupo Araxá mostram distribuição bimodal (Pimentel et al., 1999, 2001; Piuzana et al., 2003; Simões, 2005; Klein 2008), com idades modelo variando entre $1,0-1,46 \mathrm{Ga}$ e entre $1,76-2,26 \mathrm{Ga}$, sugerindo que a fonte das rochas metassedimentares do Grupo Araxá são rochas relacionadas ao Arco Magmático de Goiás (idades mais jovens) e a terrenos paleoproterozoicos (idades mais antigas). Pimentel et al. (2001) sugerem que as rochas metassedimentares com idades mais antigas representariam sequências distais de margem passiva, enquanto as rochas metassedimentares com idades mais jovens corresponderiam a sedimentos depositados em bacia tipo back arc. Entretanto, Pimentel et al. (2011) sugerem que as rochas metassedimentares do Grupo Araxá foram depositadas em bacias sin-orogênicas (talvez do tipo fore arc). Dados isotópicos $\mathrm{U} / \mathrm{Pb}$ (em cristais de zircão detríticos) e $\mathrm{Sm} / \mathrm{Nd}$ sugerem que a sedimentação do Grupo Araxá ocorreu durante o Neoproterozoico, entre 0,64 - 0,9 Ga (Navarro et al., 2013; Pimentel et al., 2001, 2011; Piuzana et al., 2003).

Apesar do grande número de trabalhos realizados no Grupo Araxá ao longo de sua extensão (Araújo et al., 1980; Barbosa et al., 1969; Barbosa et al., 1970a, b; Fuck \& Marini, 1981; Lacerda Filho et al., 1999; Moreira et al., 2008; Pimentel et al., 2001; RADAMBRASIL, 1983; Seer, 1999; Simões, 2005; Valente, 1986; Valeriano et al., 2004; Zanardo, 1992; Zanardo et al., 1996; entre muitos outros) grande parte das rochas metassedimentares do Grupo Araxá, em especial na área de estudo, carecem de estudos mais aprofundados sobre sua proveniência.

A utilização da composição química de sedimentos e de diagramas discriminantes para determinação da proveniência e do ambiente tectônico de bacias sedimentares tem sido abordada por diversos autores (Bhatia, 1983; Bhatia \& Crook, 1986; Floyd et al., 1989; Feng et al., 1993; Slack \& Stevens, 1994; Cullers, 2000, 2002; Ugarkar \& Nyamati, 2001; Basson et al., 2004; Armstrong-Altrin \& Verma, 2005; Campo \& Guevara, 2005; Selvaraj \& Chen, 2006; Armstrong-Altrin, 2009; Bakkiaraj et al., 2010; Raza et al., 2010; Campos Neto et al., 2011; Fatima \& Khan, 2012; Raza et al., 2012; Westin \& Campos Neto, 2013 Santos et al., 2015, entre outros). Muitos autores questionam a eficácia da utilização da composição química de sedimentos para determinar ambientes deposicionais e seu contexto geotectônico (Weltje, 2006, 2012; Ryan \& Williams, 2007; Pe-Piper et al., 2008; Armstrong-Altrin, 2009; Guo et al., 2011; von Eynatten \& Dunkl, 2012; Zaid, 2012, entre outros).

Entretanto, elementos terras raras (ETR), elementos traço (como Sc, Co, Th, U, Zr, Hf) e suas razões (como La/Sc, Th/Sc, Th/U, Zr/Sc, $\left.\mathrm{Cr} / \mathrm{Th}, \mathrm{Eu}_{(\mathrm{N})} / \mathrm{Eu}_{(\mathrm{N})}, \mathrm{ETRL}_{(\mathrm{N})} / \mathrm{ETRP}_{(\mathrm{N})}\right)$ são considerados eficientes para determinar as características das rochas fontes de sedimentos, uma vez que não são facilmente mobilizados 
em processos posteriores à sedimentação e/ou metamorfismo, preservando as características das rochas fontes (Cullers et al., 1974; Taylor \& McLennan, 1981, 1985; Bhatia \& Crook, 1986; McLennan et al., 1993; Roser et al., 1996; Etemad-Saeed et al., 2011; Fu et al., 2010; Zaid, 2012, entre outros). Idades U/Pb (em cristais de zircão detríticos), dados isotópicos $\mathrm{Sm} / \mathrm{Nd}$ e idades modelo $\left(\mathrm{T}_{\mathrm{DMNd}} \mathrm{N}\right.$ são também importantes ferramentas para avaliação da proveniência, estabelecendo respectivamente as idades das rochas fontes.

Este trabalho visa apresentar dados geoquímicos e isotópicos (U-Pb e Sm-Nd) das rochas metassedimentares do Grupo Araxá que ocorrem na região de Morrinhos Marcelândia, com o intuito de reconhecer as características das áreas fontes que deram origem à Unidade B de Lacerda Filho et al. (1999) nesta região.

\section{CARACTERÍSTICAS DO GRUPO ARAXÁ NA REGIÃO DE ESTUDO}

O Grupo Araxá entre Morrinhos Marcelândia (Figura 3) é constituído principalmente por rochas metassedimentares pelíticas (granada-biotita-muscovita xistos, biotita/muscovita xistos, hornblenda-granadabiotita paragnaisses, granada-biotita-muscovita paragnaisses, hornblenda-granada-biotita paragnaisses, localmente com cianita e estaurolita), com intercalações de rochas metassedimentares psamíticas/psamo-pelíticas (quartzitos, muscovita quartzitos, quartzo xistos, biotita-muscovitaquartzo xistos), lentes de metamá-ficas (anfibolito, granada anfibolito) e de metaultramáficas (serpentinito, talco xisto, clorita xisto, tremolita/actinolita xisto) (Simões, 2005; Navarro et al., 2013).

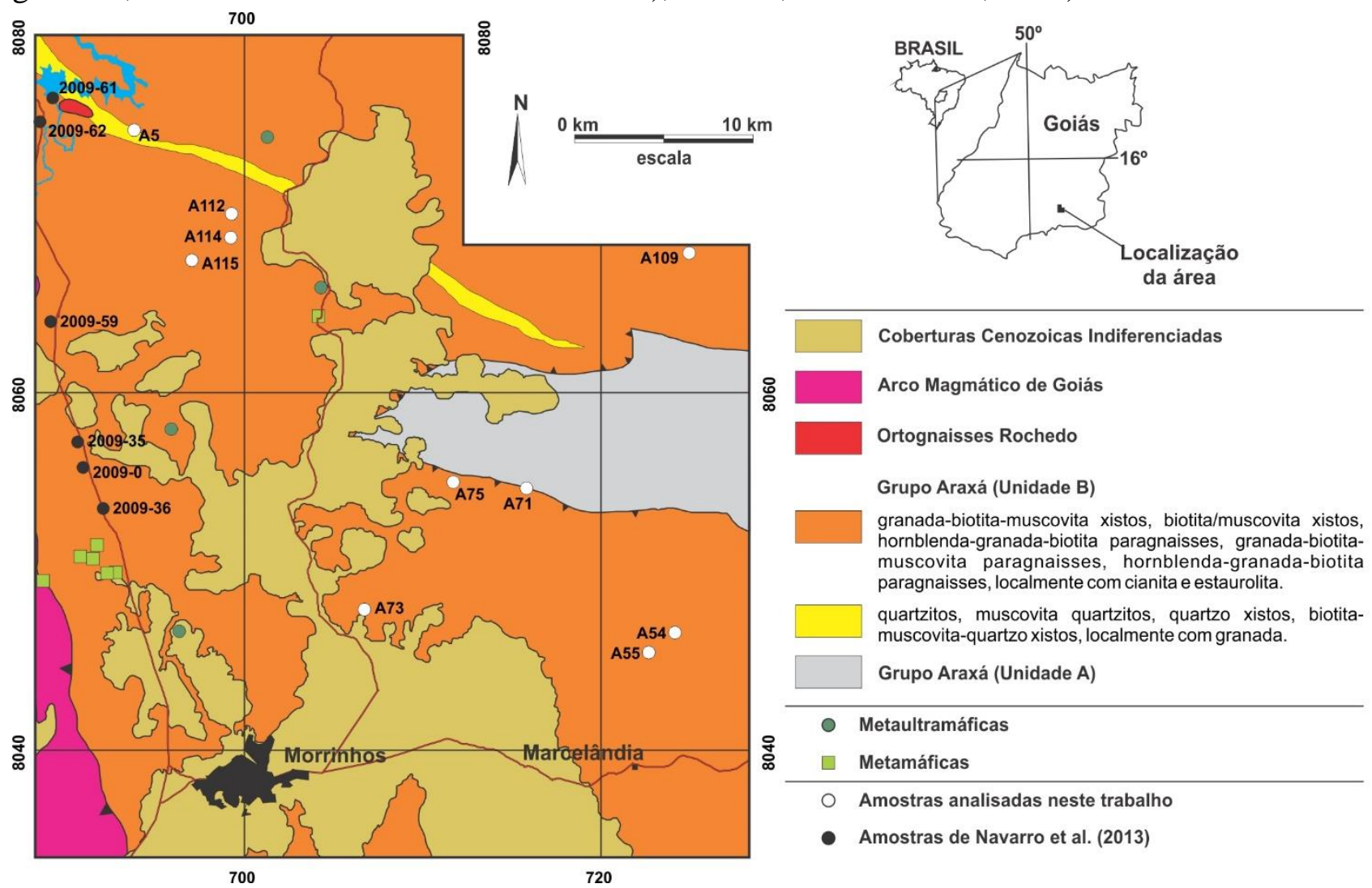

Figura 3. Mapa geológico simplificado da área de estudo, mostrando a localização das amostras analisadas (mod. de Simões, 2005; Moreira et al., 2008).

Corpos graníticos intrusivos no Grupo Araxá (Figura 3), denominados informalmente de ortognaisses Rochedo (Navarro et al., 2014), ocorrem na porção NW da área. São corpos ovalados com orientação geral E-W, representados por biotita-muscovita ortognaisse e muscovita ortognaisse, com composição variando entre tonalito e granodiorito. Quimicamente estes corpos graníticos são peraluminosos, cálcioalcalinos e são classificados como do tipo-S e/ou MPG (Muscovite-bearing Peraluminous Granitoids). As características químicas sugerem que estes corpos graníticos derivam da fusão parcial de rochas metassedimentares do Grupo Araxá (Navarro et al., 2014).

Associações minerais relacionadas ao pico 
metamórfico nas rochas metassedimentares do Grupo Araxá na área de estudo são típicas da fácies anfibolito médio a superior, caracterizadas por biotita + oligoclásio/andesina + granada + hornblenda; biotita + plagioclásio + granada e/ou granada + oligoclásio/andesina + biotita \pm cianita, todas contendo quartzo e muscovita, sendo rutilo e ilmenita os principais óxidos associados. $\mathrm{O}$ pico metamórfico registrado nas rochas do Grupo Araxá é correlacionável à fase deformacional pré- a sinDn (regional). Dados termobarométricos mostram que o pico metamórfico ocorreu a $610^{\circ} \mathrm{C}$ e $\sim 10 \mathrm{kbar}$, em condições de fácies anfibolito, zona da cianita, e sugerem trajetória P-T horária, típica de cinturões colisionais (Navarro et al., 2009, 2011).

Idades modelo de rochas metassedimentares do Grupo Araxá entre Mairipotaba - Morrinhos variando entre $1,25-1,51 \mathrm{Ga}$ e entre $1,76-2,26$ Ga (Navarro et al., 2012, 2013), sugerem que a fonte das rochas metassedimentares do Grupo Araxá são rochas neoproterozoicas (Arco Magmático de Goiás) e rochas mais antigas (terrenos paleoproterozoicos), como observado em outras regiões da Faixa Brasília (Pimentel et al., 1999, 2001; Piuzana et al., 2003; Simões, 2005; Klein, 2008).

Dados isotópicos U/Pb (análise LA-ICP-MS em cristais de zircão detríticos) em uma amostra do Grupo Araxá, na região de Morrinhos (Navarro et al., 2013), também sugerem que a sedimentação do Grupo Araxá ocorreu durante o neoproterozoico, entre 0,64 - 0,9 Ga como sugerido por outros autores (Pimentel et al., 2001; Piuzana et al., 2003; Hasui, 2012).

\section{MÉTODOS ANALÍTICOS}

Foram selecionadas 10 amostras de rochas metassedimentares do Grupo Araxá que ocorrem entre Morrinhos -Marcelândia (GO) para estudos litogeoquímicos de elementos maiores, menores e traços. As análises químicas foram realizadas pelo Laboratório Acme (Analytical Laboratories LTD, Vancouver, Canadá).

Os elementos maiores foram analisados por Espectrômetro de Emissão em Plasma Indutivamente Acoplado (ICP-ES) e os elementos traço foram analisados no Espectrômetro de Massa em Plasma Indutivamente Acoplado (ICP-MS). Os resultados das análises geoquímicas são apresentados na Tabela 1 (Apêndice, ao final do artigo), e a localização das amostras, na Figura 3.

Seis amostras (A5, A54, A55, A73, A109, A115) foram selecionadas para análises isotópicas $\mathrm{Sm} / \mathrm{Nd}$. As análises isotópicas foram feitas no Laboratório de Geocronologia e Isótopos Radiogênicos (LAGIR), da Faculdade de Geologia, da Universidade do Estado do Rio de Janeiro, segundo o método descrito por
Valeriano et al. (2009). As leituras das razões foram realizadas utilizando o espectrômetro de massa por ionização térmica TRITON-TI. A razão ${ }^{143} \mathrm{Nd} /{ }^{144} \mathrm{Nd}$ foi normalizada em função da razão ${ }^{146} \mathrm{Nd} /{ }^{144} \mathrm{Nd}$ de 0,7219 (La Jolla). Os valores de TDM foram calculados usando o modelo de De Paolo (1981). Os resultados das análises são mostrados na Tabela 2 (Apêndice, ao final do artigo).

Quatro amostras (A54, A73, A109, A115) foram selecionadas para estudos de proveniência (idades $\mathrm{U} / \mathrm{Pb}$ em cristais de zircão detríticos por LA-ICP-MS). As análises isotópicas U/Pb foram feitas no Laboratório de Geocronologia, do Instituto de Geociências, da Universidade Federal de Brasília (UnB), segundo o método descrito por Bühn et al. (2009).

As leituras das razões foram realizadas por espectrômetro de massa multicoletor com ablação a laser (LA-ICP-MS), modelo Finnigan MAT 262 em modo estático. Os resultados das análises de cristais de zircão são mostrados na Tabela 3 (Apêndice, ao final do artigo).

\section{RESULTADOS E DISCUSSÕES}

As rochas metassedimentares do Grupo Araxá analisadas correspondem a xistos (muscovitabiotita xistos com granada) e paragnaisses (biotitamuscovita paragnaisse com ou sem granada e hornblenda, granada-biotita gnaisse e granadamuscovita-gnaisse com ou sem cianita). Possuem grande variação nos teores de $\mathrm{SiO}_{2}$, variando entre $58,29 \%$ e $73,53 \%$, de $\mathrm{Al}_{2} \mathrm{O}_{3}$ entre $12,70 \%$ e $18,76 \%$, de $\mathrm{Fe}_{2} \mathrm{O}_{3}{ }^{\mathrm{T}}$ entre $4,29 \%$ e $10,22 \%$ e de $\mathrm{K}_{2} \mathrm{O}$ entre $1,20 \%$ e $4,79 \%$. O conteúdo de $\mathrm{MgO}$ varia entre $1,20 \%$ a $3,66 \%$, o de $\mathrm{CaO}$ entre $0,10 \%$ a $5,10 \%$, o de $\mathrm{TiO}_{2}$ entre $0,52 \%$ a $1,10 \%$, o de $\mathrm{MnO}$ entre $0,06 \%$ a $0,17 \%$, o de $\mathrm{P}_{2} \mathrm{O}_{5}$ entre $0,10 \%$ a $0,21 \%$ e o de $\mathrm{Na}_{2} \mathrm{O}$ varia entre $0,07 \%$ a $3,18 \%$. Nos diagramas tipo Harker (Figura 4) observa-se correlações negativas de $\mathrm{Al}_{2} \mathrm{O}_{3}, \mathrm{Fe}_{2} \mathrm{O}_{3}{ }^{\mathrm{T}}, \mathrm{MgO}$ e $\mathrm{P}_{2} \mathrm{O}_{5}$ em relação a $\mathrm{SiO}_{2}$, enquanto $\mathrm{TiO}_{2}, \mathrm{MnO}$, $\mathrm{CaO}, \mathrm{Na}_{2} \mathrm{O}$ e $\mathrm{K}_{2} \mathrm{O}$ não apresentam correlações. 

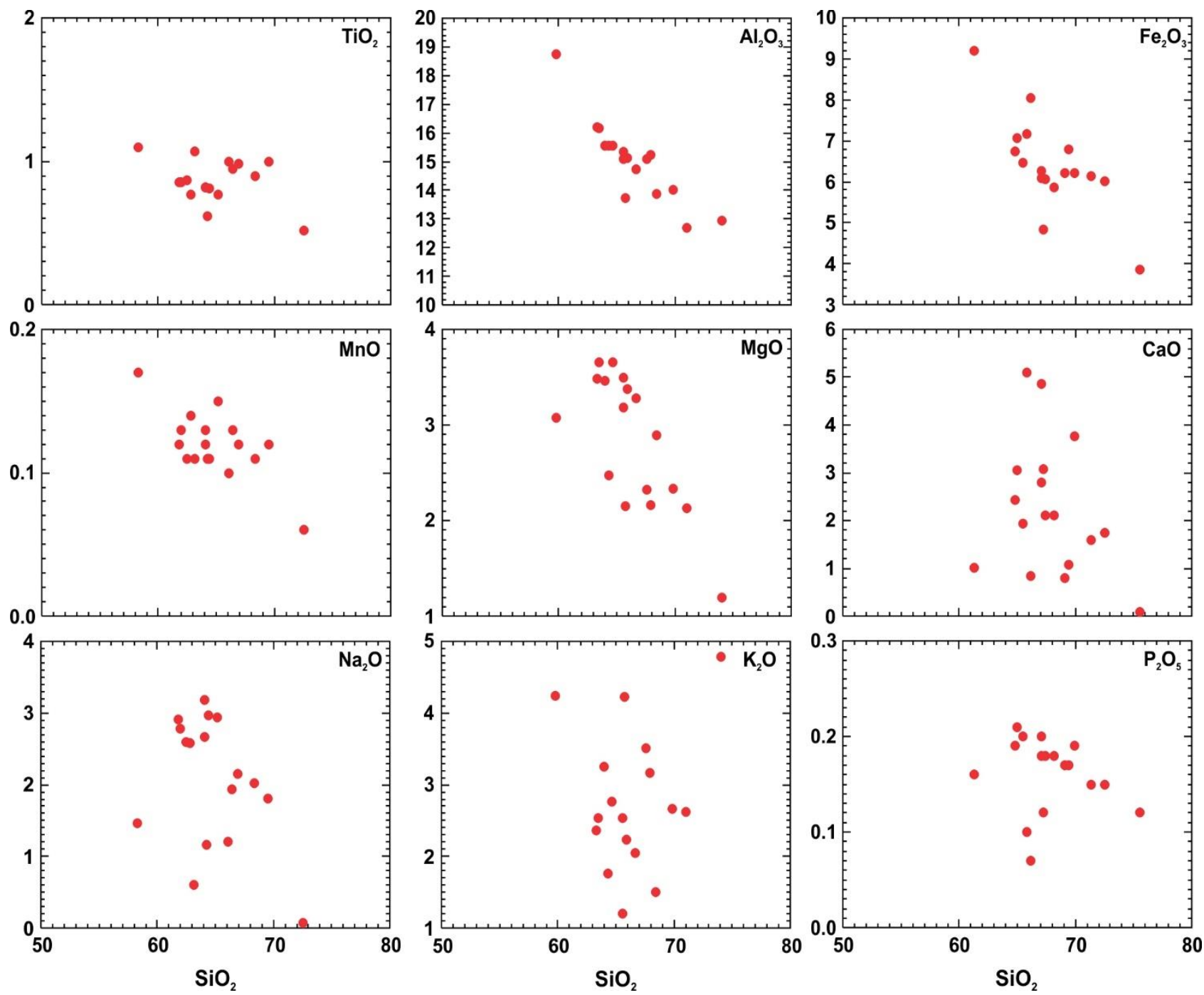

Figura 4. Diagramas do tipo Harker para elementos maiores (\% óxidos) $x \mathrm{SiO}_{2}$.

Possuem pequena variação no conteúdo de Hf $(4,4-7,8 \mathrm{ppm}), \mathrm{Nb}(7,5-18,5 \mathrm{ppm}), \mathrm{Ta}$ $(0,5-1,3 \mathrm{ppm}), \mathrm{Ga}(14,3-25,8 \mathrm{ppm})$ e $\mathrm{U}(1,1$ $-2,7 \mathrm{ppm})$, grande variação nos teores de $\mathrm{V}$ (58,0 - 159,0 ppm), Rb (34,1 - 249,7 ppm), Sr (25,5 - 305,6 ppm), Ba (280,0 - 1084,0 ppm), $\mathrm{Zr}(156,9$ - 282,5 ppm), Cr (54,74 - 205,26 ppm) e Ni (10,4 a 69,7 ppm). Os teores de Cs variam de 1,3 a 9,1 ppm, de Y variam entre 23,4 a 124,3 ppm, de Th varia entre 3,4 a 15,1 ppm, de Sc entre 8,0 a 23 ppm e de $\mathrm{Pb}$ varia entre 1,3 a 13,4 ppm. Nos diagramas tipo Harker (Figura 5) não se observam trends em relação a $\mathrm{Ba}, \mathrm{Rb}, \mathrm{Sr}, \mathrm{Nb}, \mathrm{Ta}, \mathrm{Zr}, \mathrm{Hf}, \mathrm{Y}, \mathrm{Th}, \mathrm{U}$ e $\mathrm{Pb}$ em relação ao teor de $\mathrm{SiO}_{2}$, e observam-se fracas correlações negativas em relação a $\mathrm{Sr}$ e Ga.

O padrão de distribuição de elementos traço (Cs, Ba, Rb, Th, U, Nb, Ta, Pb, Sr, Zr, Hf e Y), elementos terras raras (ETR), K (em ppm), $\mathrm{P}$ (em ppm) e Ti (em ppm), quando normalizados pelo manto primitivo (Taylor \& McLennan,
1985), mostram que estas rochas metassedimentares são enriquecidos em $\mathrm{Cs}, \mathrm{K}, \mathrm{Ba}$, $\mathrm{Rb}, \mathrm{Th}, \mathrm{U}, \mathrm{Pb}$ e ETRL (elementos terras raras leves) em relação ao manto primitivo, mostrando fracas a médias anomalias negativas de Nb, Ta, Sr, P, Eu e Ti (Figura 6A).

A distribuição dos ETRP apresenta um padrão pouco inclinado a sub-horizontal, indicando fraco fracionamento entre os ETRP $\left(\mathrm{Gd}_{\mathrm{N}} / \mathrm{Lu}_{\mathrm{N}}=1,14-2,05\right)$. A relação entre ETRL e ETRP mostra forte fracionamento $\left(\mathrm{La}_{\mathrm{N}} / \mathrm{Lu}_{\mathrm{N}}\right.$ $=4,40-14,15)$, exibindo discretas a fortes anomalias negativas de $\mathrm{Eu}\left(\mathrm{Eu}^{*}=0,43-0,81\right)$ (Figura 6B).

As rochas metassedimentares do Grupo Araxá na região possuem razões $\mathrm{La}_{(\mathrm{N})} / \mathrm{Lu}_{(\mathrm{N})}$ $(4,40-14,15), \mathrm{La} / \mathrm{Sc}(0,89-11,67), \mathrm{Th} / \mathrm{Sc}$ $(0,155$ - 1,875), La/Co $(0,944-11,13), \mathrm{Th} / \mathrm{Co}$ $(0,199-1,948)$ e $\mathrm{Cr} / \mathrm{Th}(4,984$ - 30,186) que sugerem que a principal fonte destes sedimentos são rochas ígneas félsicas (Rahman \& Suzuki, 2007; Raza et al., 2010). 

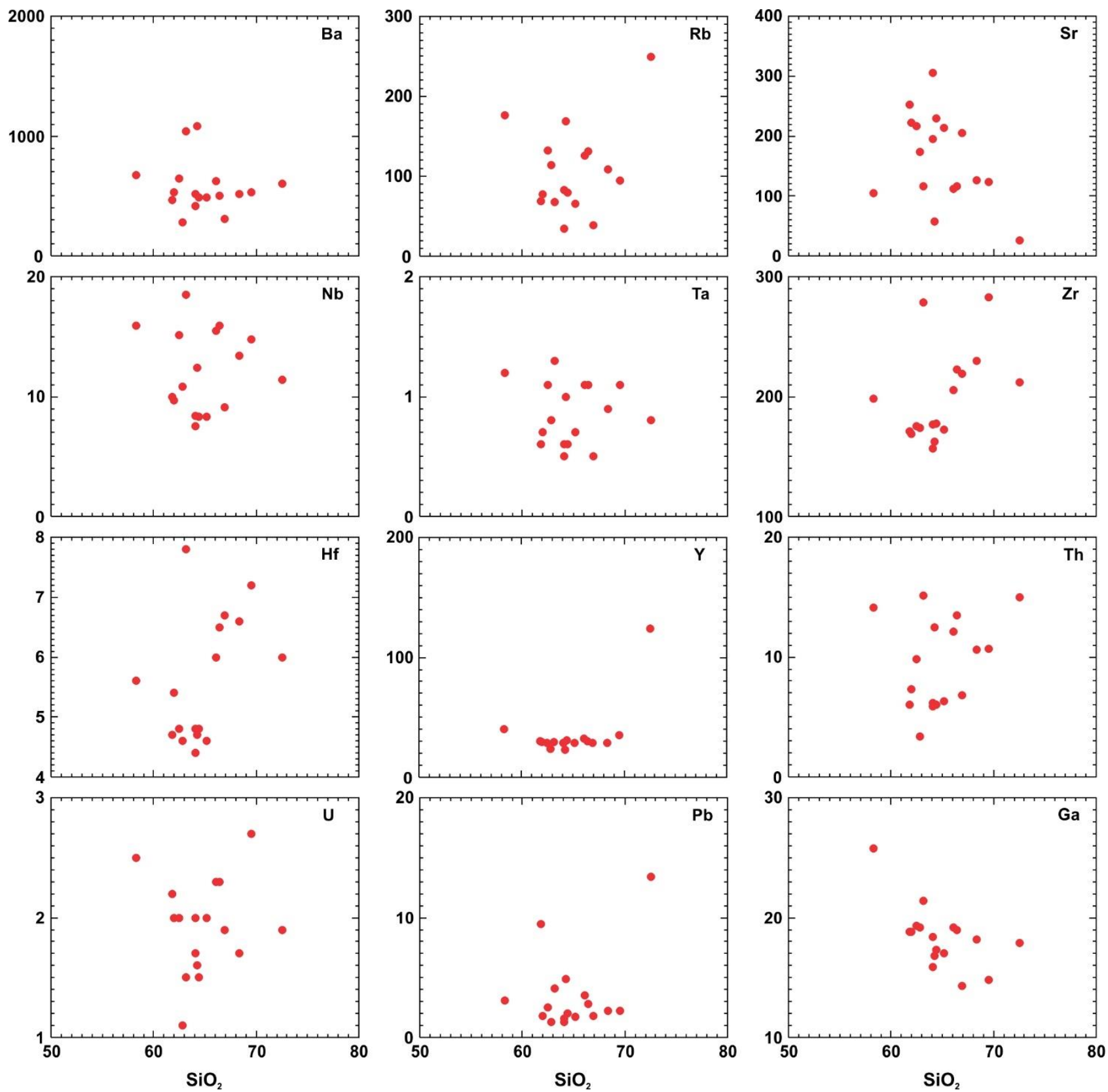

Figura 5. Diagramas do tipo Harker para elementos traços (Ba, Rb, Sr, Nb, Ta, Zr, Hf, Y, Th, U, Pb, Ga em ppm) $x \mathrm{SiO}_{2}$.
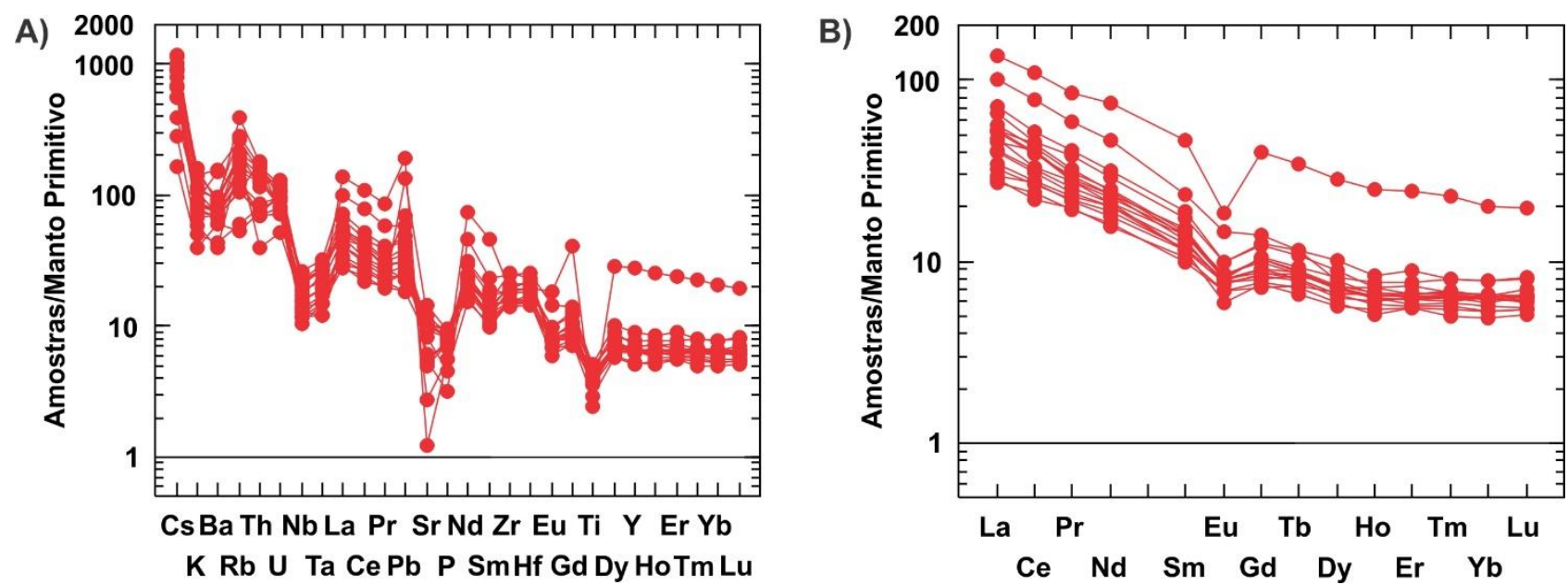

Figura 6. (A) Padrão de distribuição de elementos menores/traços, maiores (K, P, Ti em ppm) e ETR normalizados pelo Manto Primitivo (Taylor \& McLennan, 1985) para as amostras analisadas; (B) Padrão de distribuição de ETR normalizados pelo Manto Primitivo (Taylor \& McLennan, 1985) para as amostras analisadas. 
No diagrama Th/Sc versus $\mathrm{Zr} / \mathrm{Sc}$ (Figura 7) as amostras analisadas concentram-se próximo ao limite proposto por McLennan et al. (1993) para a mudança de uma tendência de variação composicional da rocha fonte dos sedimentos, relacionada com processos ígneos e o início de um processo de reciclagem sedimentar, preservando, contudo, o trend associado a rochas ígneas.

Segundo Taylor \& McLennan (1985), rochas sedimentares com razão Th/Sc > 1 sugerem que a fonte de sedimentos são rochas ígneas bastante evoluídas, enquanto a razão $\mathrm{Th} / \mathrm{Sc}<0,8$ refletem contribuições de fontes máficas. Razões $\mathrm{Zr} / \mathrm{Sc}>$ 10 e $\mathrm{Th} / \mathrm{U}>4$ sugerem uma fonte matura ou reciclagem de sedimentos (Tripathi \& Rajamani, 2003) (Figura 7).

Estas razões aplicadas aos metassedimentos do Grupo Araxá sugerem uma fonte matura de

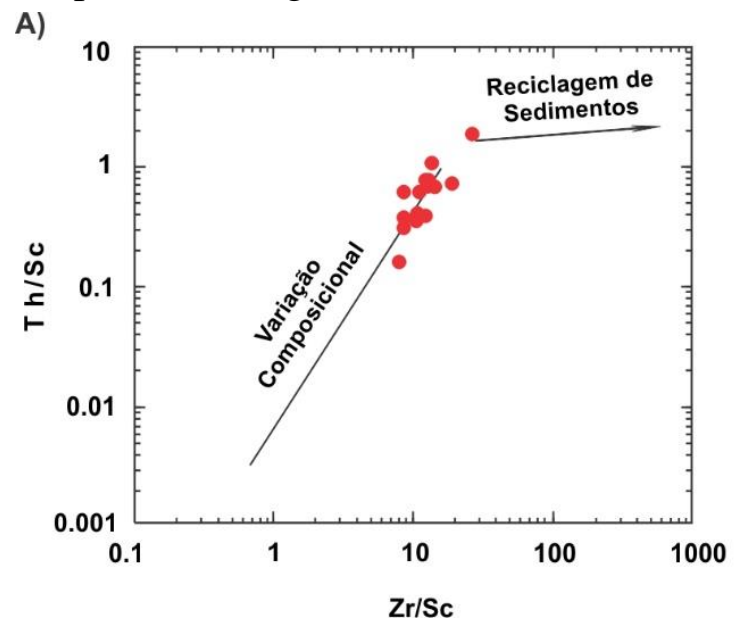

rochas félsicas de composição intermediária.

Bhatia \& Crook (1986) propuseram a utilização de diagramas binários (Ti/Zr versus $\mathrm{La} / \mathrm{Sc}$ e La/Y versus $\mathrm{Sc} / \mathrm{Cr}$ ) e ternários (La-ThSc, Th-Co-Zr/10 e Th-Sc-Zr/10) para caracterizar a proveniência de sedimentos e determinar o ambiente tectônico de sedimentação.

A utilização destes diagramas para as amostras analisadas sugere que a fonte das rochas metassedimentares são rochas formadas em arcos magmáticos (Figura 8A, B, C, D, E).

Os diagramas discriminantes $\mathrm{TiO}_{2}$ versus $\mathrm{Fe}_{2} \mathrm{O}_{3}{ }^{\mathrm{T}}+\mathrm{MgO},\left(\mathrm{Al}_{2} \mathrm{O}_{3} / \mathrm{SiO}_{2}\right)$ versus $\mathrm{Fe}_{2} \mathrm{O}_{3}{ }^{\mathrm{T}}+\mathrm{MgO}$, $\left(\mathrm{K}_{2} \mathrm{O} / \mathrm{Na}_{2} \mathrm{O}\right) \quad$ versus $\mathrm{Fe}_{2} \mathrm{O}_{3}{ }^{\mathrm{T}}+\mathrm{MgO}$, $\left(\mathrm{Al}_{2} \mathrm{O}_{3} / \mathrm{CaO}+\mathrm{Na}_{2} \mathrm{O}\right)$ versus $\mathrm{Fe}_{2} \mathrm{O}_{3} \mathrm{~T}+\mathrm{MgO}$ (Bhatia, 1983) também sugerem similaridades químicas com sedimentos de ambientes de arcos de ilha continentais (Figura 8F, G, H, I).

B)

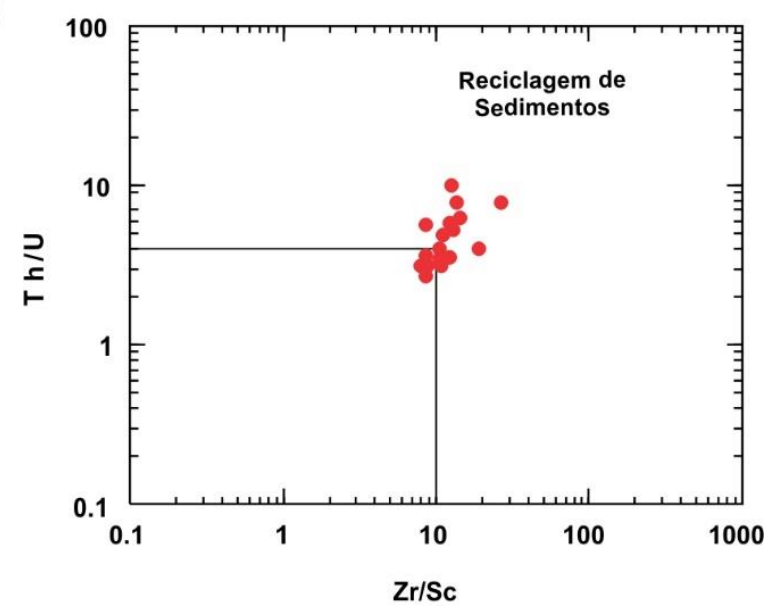

Figura 7. A) Diagrama Th/Sc x Zr/Sc (McLennan et al., 1993); B) Diagrama Th/U x Zr/Sc (modificado de Taylor \& McLennan, 1985) das amostras analisadas.

As razões isotópicas ${ }^{147} \mathrm{Sm} /{ }^{144} \mathrm{Nd}$ e ${ }^{143} \mathrm{Nd} /{ }^{147} \mathrm{Nd}$ (Tabela 2) obtidas para as amostras de rochas metassedimentares do Grupo Araxá na região de Morrinhos - Marcelândia revelam idades $\mathrm{T}_{\mathrm{DM}} \mathrm{Nd}$ variando entre 1,25 e 1,93 Ga, $\varepsilon \mathrm{Nd}_{(0)}$ entre $-12,87$ e $-5,15$, razões ${ }^{147} \mathrm{Sm} /{ }^{144} \mathrm{Nd}$ variando entre $0,1215-0,140$ e de ${ }^{143} \mathrm{Nd} /{ }^{147} \mathrm{Nd}$ variando entre $0,51198-0,512374$.

Os resultados são semelhantes a dados isotópicos em rochas metassedimentares do Grupo Araxá em outras regiões do Estado de Goiás (Pimentel et al., 1999, 2001; Piuzana et al., 2003; Simões, 2005; Klein, 2008; Navarro et al., 2013), que mostram valores ${ }^{147} \mathrm{Sm} /{ }^{144} \mathrm{Nd}$ entre $0,079-$ 0,234 e ${ }^{143} \mathrm{Sm} /{ }^{144} \mathrm{Nd}$ entre $0,511397-0,512446$, além de $\mathrm{T}_{\mathrm{DMNd}}$ variando entre 1,00 - 2,26 Ga, distribuindo-se em dois conjuntos, um com $\mathrm{T}_{\mathrm{DMN}} \mathrm{Nd}$ entre 1,00 e 1,46 Ga e outro com $\mathrm{T}_{\mathrm{DMNd}}$ entre 1,76 e 2,26 Ga (Figura 9). A presença marcante de rochas metassedimentares com $\mathrm{T}_{\mathrm{DM}} \mathrm{Nd}$ variando entre $1,1-1,3 \mathrm{Ga}$ no Grupo Araxá sugere uma fonte neoproterozoica para a origem dos sedimentos, provavelmente rochas relacionadas ao Arco Magmático de Goiás. As idades mais antigas teriam como fonte rochas relacionadas ao Cráton do São Francisco (Pimentel et al., 1999, 2001; Piuzana et al., 2003; Klein, 2008; Navarro et al., 2013).

As razões isotópicas ${ }^{147} \mathrm{Sm} /{ }^{144} \mathrm{Nd}$ e ${ }^{143} \mathrm{Nd} /{ }^{147} \mathrm{Nd}$ (Tabela 2) obtidas para as amostras de rochas metassedimentares do Grupo Araxá na região de Morrinhos - Marcelândia revelam idades $\mathrm{T}_{\mathrm{DM}} \mathrm{Nd}$ variando entre 1,25 e 1,93 Ga, ${ }_{\varepsilon} \mathrm{Nd}_{(0)}$ entre $-12,87$ e $-5,15$, razões ${ }^{147} \mathrm{Sm} /{ }^{144} \mathrm{Nd}$ variando entre $0,1215-0,140$ e de ${ }^{143} \mathrm{Nd} /{ }^{147} \mathrm{Nd}$ variando entre $0,51198-0,512374$. 
A)
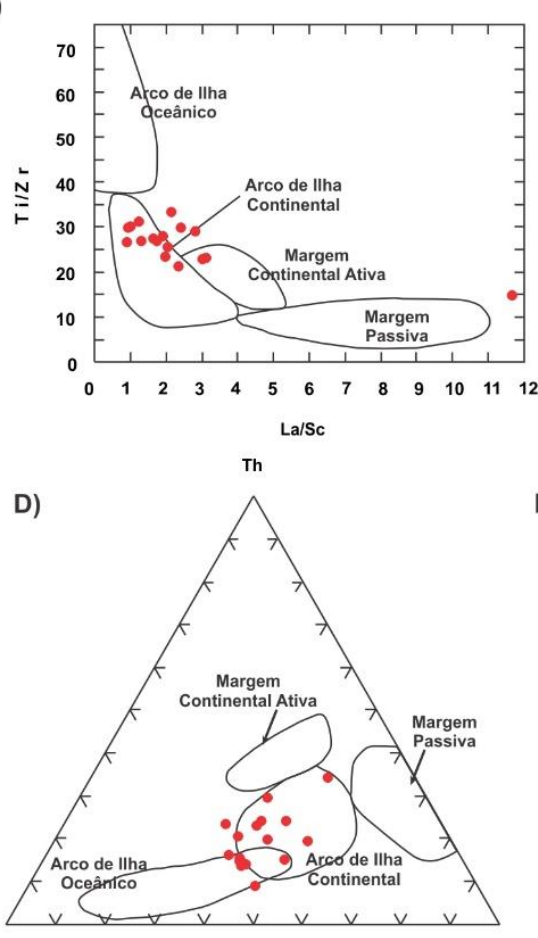

Co

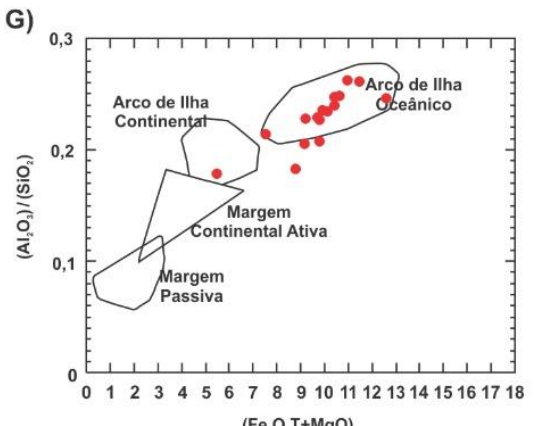

B)

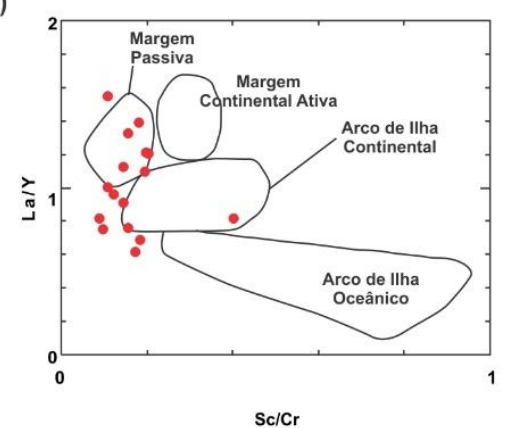

E)

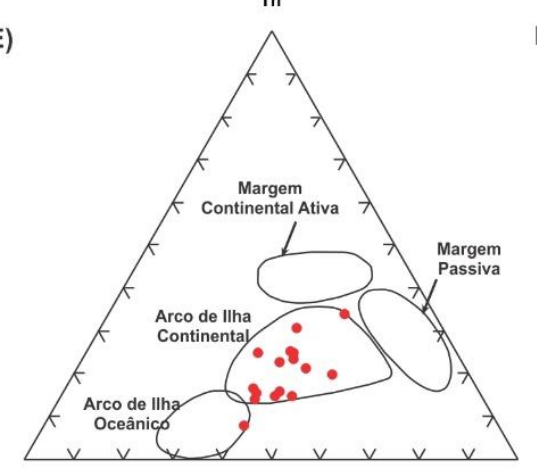

C)

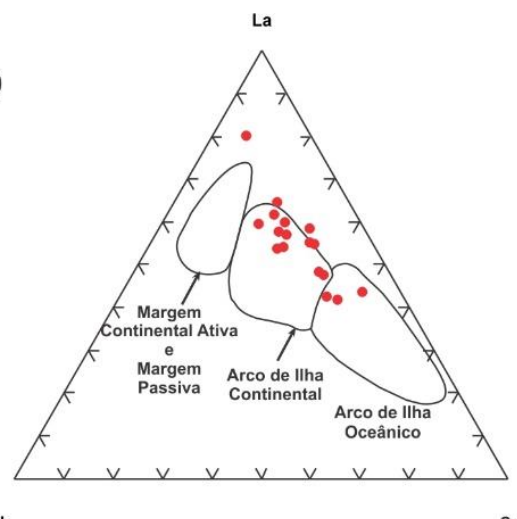

F)

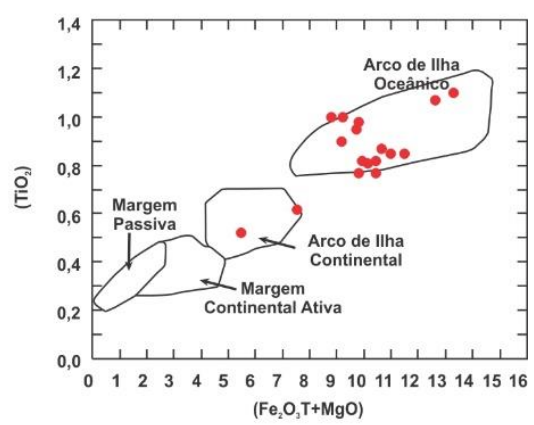

$\mathrm{Zr} / 10 \mathrm{Sc}$

$\mathrm{zr} / 10$

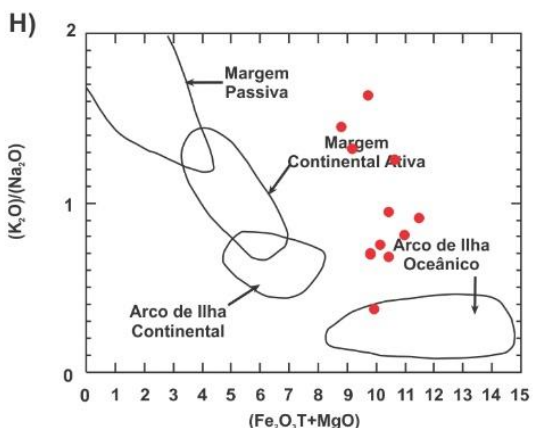

I)

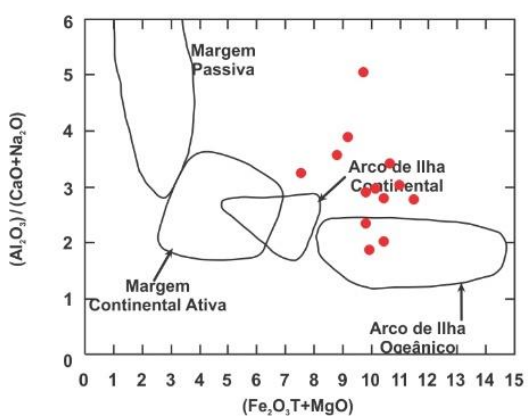

Figura 8. Diagramas discriminantes das amostras analisadas. A), B), C), D) e E) Bhatia \& Crook (1986), F), G), H) e I) Bhatia (1983).
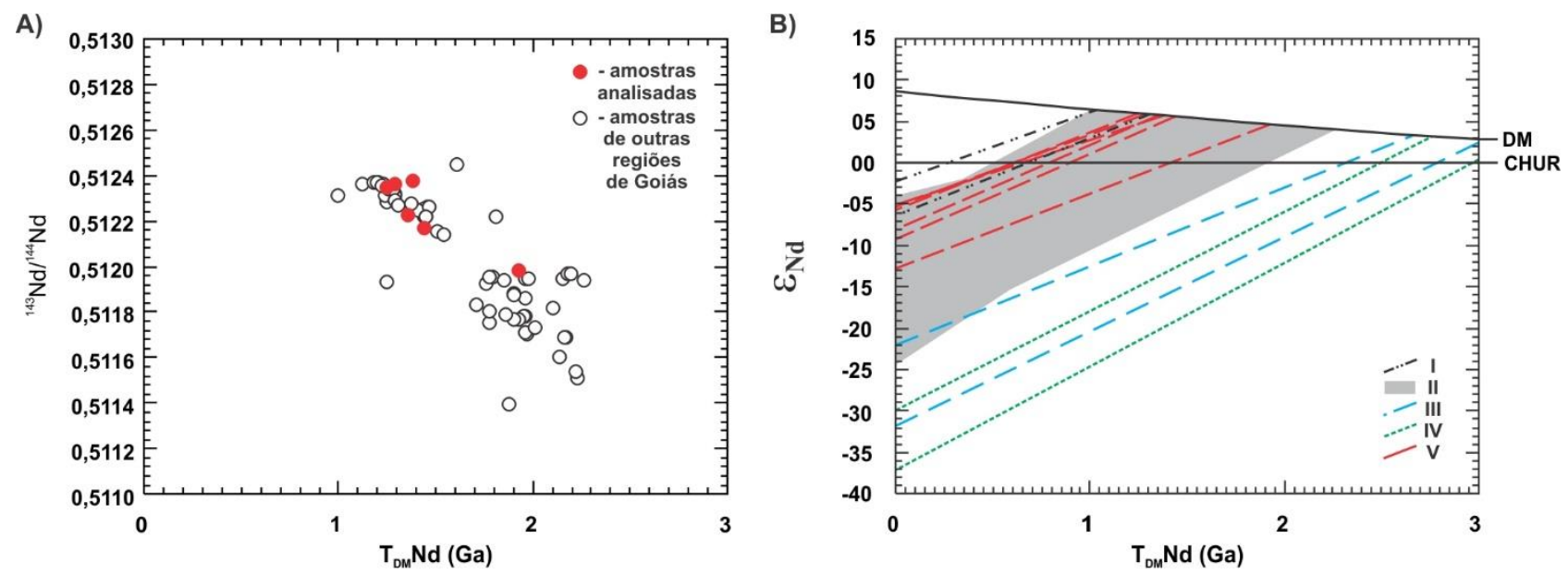

I - Composição isotópica de rochas do Arco Magmático de Goiás (Pimentel e Fuck, 1992)

II - Composição isotópica de rochas metassedimentares do Grupo Araxá, na porção sul do Estado de Goiás

(Pimentel et al., 1999, 2001; Piuzana et al., 2003; Simões, 2005; Klein, 2008; Navarro et al., 2013)

III - Composição isotópica de rochas do Cráton do São Francisco (Pimentel et al., 2001)

IV - Composição isotópica de rochas do Maciço Mediano de Goiás (Pimentel et al., 1996)

V - Composição isotópica das amostras analisadas neste trabalho

Figura 9. A) Composição isotópica ${ }^{143} \mathrm{Nd} /{ }^{144} \mathrm{Nd}$ e idades modelo das amostras analisadas. B) Variação dos valores de ENd no tempo geológico das amostras analisadas (modificado de Navarro et al., 2013). 
Foram analisados 224 grãos de cristais de zircão (41 cristais de zircão da amostra A54, 61 cristais de zircão da amostra A73, 61 cristais de zircão da amostra A109, 61 cristais de zircão da amostra A115), por LA-ICP-MS. As idades obtidas variam em 3 conjuntos (Figura 10): o primeiro grupo variando entre $\sim 600$ a $\sim 1100 \mathrm{Ma}(129$ cristais de zircão), o segundo grupo variando entre $>1100 \mathrm{e}$
1500 Ma (60 cristais de zircão), e o terceiro com idades maiores que $1,7 \mathrm{Ga}$ (38 cristais de zircão, com idades entre 1715 a 2731).

As idades obtidas mostram que os cristais de zircão de idade neoproterozoica são os mais abundantes $(<900 \mathrm{Ma})$, indicando que a principal fonte desses sedimentos são rochas neoproterozoicas (Figura 10).
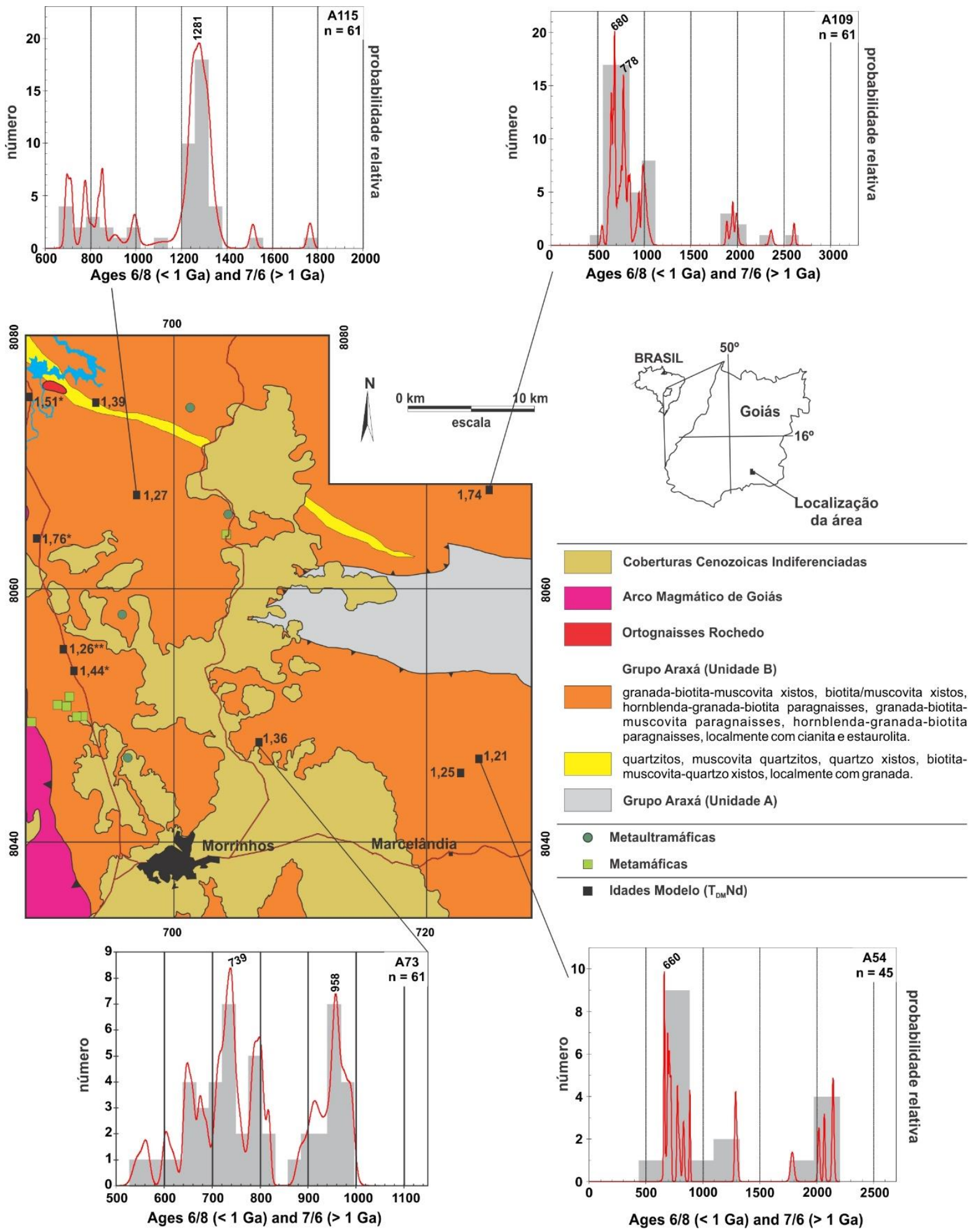

Figura 10 - Mapa geológico simplificado com a localização das amostras analisadas, idades modelo e os respectivos histogramas das idades dos cristais de zircão detríticos analisados. * idades compiladas de Navarro et al. (2013). ** idade compilada de Pimentel et al. (2000) 


\section{CONCLUSÃO}

As razões $\mathrm{La}_{(\mathrm{N})} / \mathrm{Lu}_{(\mathrm{N})}, \mathrm{La} / \mathrm{Sc}, \mathrm{Th} / \mathrm{Sc}, \mathrm{La} / \mathrm{Co}$, $\mathrm{Th} / \mathrm{Co}, \mathrm{Cr} / \mathrm{Th}$ e $\mathrm{Th} / \mathrm{U}$ obtidas para as amostras de rochas metassedimentares do Grupo Araxá na região de Morrinhos - Rochedo - Marcelândia, sugerem que estas rochas são derivadas de rochas ígneas félsicas. As idades modelo $\mathrm{T}_{\mathrm{DM}} \mathrm{Nd}$ obtidas possuem valores entre 1,21 e 1,76 Ga, sugerindo duas fontes para as rochas metassedimentares, uma fonte neoproterozoica (Arco Magmático de Goiás) e outra mais antiga relacionada a rochas mesopaleoproterozoicas. As idades $\mathrm{U} / \mathrm{Pb}$ em cristais de zircão também sugerem a contribuição de uma fonte neoproterozoica $(<1,0 \quad \mathrm{Ga})$ e uma contribuição de outra fonte mais antiga mesoproterozoica $(>1,0 \mathrm{Ga})$. A congruência destes dados geocronológicos com as assinaturas geoquímicas das rochas analisadas permite afirmar que grande parte das rochas metassedimentares do Grupo Araxá na região tem como fonte rochas formadas em arcos magmáticos neoproterozoicos.

As idades $\mathrm{U} / \mathrm{Pb}$ obtidas em cristais de zircão para as rochas metassedimentares da Nappe de Passos (Valeriano et al., 2004) são predominantemente mesoproterozoicas ou mais antigas $(>1,2 \mathrm{Ga})$, enquanto as idades obtidas para as fontes das rochas metassedimentares do Grupo Araxá na região de Morrinhos - Marcelândia são predominantemente neoproterozoicas $(<1,0 \mathrm{Ga})$, com contribuições restritas de fontes mais antigas $(>1,0 \mathrm{Ga})$, sugerindo duas fontes distintas e/ou provavelmente ambientes deposicionais diferentes, para as rochas metassedimentares da "Bacia Araxá".

Para Dardenne (2000), Trouw et al. (2000) e Valeriano et al. (2004) as rochas metassedimentares da Nappe de Passos são parte de uma sequência sedimentar de margem passiva que se estabeleceu no entorno do Cráton do São Francisco durante o Neoproterozoico. Entretanto, as rochas metassedimentares da região de Morrinhos Marcelândia possuem assinaturas químicas de sedimentos derivados de rochas formadas em arcos magmáticos.

Como as características químicas/ mineralógicas dos sedimentos são influenciadas pela proximidade com a área fonte e com o tipo de litologias que compõem essa área, os dados apresentados indicam que os sedimentos do Grupo Araxá foram depositados em bacias tipo fore arc, durante o neoproterozoico.

\section{AGRADECIMENTOS}

Os autores agradecem à Fundação de Amparo à Pesquisa do Estado de São Paulo (FAPESP), processo 2013/04235-2.

\section{REFERÊNCIAS}

ARAÚJO, V.A.; GODOI, P.V.B.; ARAUJO, H.O.; MORETON, E.S.; SILVA, L.C.; SA, M.A.D.; MARTINS, A.M.; MATOS, E.G, ANDRADE, S.H.S.; SALES, R., BEBERT, C.O.; OLIVATTI, O. Projeto Pontalina - Fase I. Goiânia: SURGEO/GO, DNPM, CPRM. 1980, 7v.

ARMSTRONG-ALTRIN, J.S. Provenance of sands from Cazones, Acapulco, and Bahía Kino beaches, Mexíco. Rev. Mex. Cienc. Geol., v. 26, n. 3), p. 764-782, 2009.

ARMSTRONG-ALTRIN, J.S. \& VERMA, S.P. Critical evaluation of six tectonic setting discrimination diagrams using geochemical data of Neogene sediments from known tectonic settings. Sedimentary Geology, v. 177, p. 115-129, 2005.

BAKKIARAJ, D.; NAGENDRA, R.; NAGARAJAN, R.; ARMSTRONG-ALTRIN, J.S. Geochemistry of sandstones from the Upper Cretaceous Sillakkudi Formation, Cauvery Basin, southern India: implication for provenance. J. Geol. Soc. India, n. 76, p. 453-467, 2010.

BARBOSA, O. Guia de excursão. In: CONGRESSO BRASILEIRO DE GEOLOGIA, IX, Araxá, 1955. Noticiário... Araxá: Sociedade Brasileira de Geologia, $\mathrm{n}^{\circ}$ 3, p 1-7.

BARBOSA, O.; BRAUN, O.P.G.; CARTNER-DYER, R.; CUNHA, C.A.B. Geologia da Região do Triângulo Mineiro. Ministério das Minas e Energia (MME), Departamento Nacional da Produção Mineral (DNPM), Divisão de Fomento da Produção Mineral (DFPM). Rio de Janeiro, Boletim 136, 210p, 1970a.

BARBOSA, O.; BAPTISTA, M. B.; INDA, H., MARCHETTO, M.; ARAÚJO, A.G.; BRAUN, O.P.C.; FRANTIN, O.; CARTNER-DYER, R., REN, C.; MENEGUESSO, G.; ANDRADE, R.; SEIXAS, S.R.M.; REIS, A.; COTTA, J.C.; SILVA, W.G.; DUTRA, C.V. Projeto Goiânia - Relatório Preliminar. Ministério das Minas e Energia (MME), Departamento Nacional da Produção Mineral (DNPM), $6^{\circ}$
Distrito Centro-Oeste, Prospec S.A. 74p., 1970b.

BARBOSA, O.; SORIANO, C.R.; ARRUDA, M., BAPTISTA, M.B.; CARTNER-DYER, R.; BRAUN, O.P.G.; INDA, H.; MARCHETTO, M.; FRATIN, O.; SEIXAS, S.R.M.; MENEGUESSO, G.; REN, C.; COTTA, J.C. Projeto Brasília - Goiás. Ministério das Minas e Energia (MME), Departamento Nacional da Produção Mineral (DNPM), Prospec S.A. 225 p., 1969.

BASSON, I.J.; PERRITT, S.; WATKEYS, M.K.; MENZIES, A.H. Geochemical Correlation Between Metasediments of the Mfongosi Group of the Natal Sector of the Namaqua-Natal Metamorphic Province, South Africa and the Ahlmannryggen. Group of the Grunehogna Province, Antarctica. Gondwana Research, v. 7, p. 1, p. 57-73, 2004.

BHATIA, M.R. Plate tectonics and geochemical composition of sandstones. The Journal Of Geology, Chicago, v. 91, n. 6, p. 611-627, 1983.

BHATIA, M.R. \& CROOK, K.A.W. Trace element characteristics of graywackes and tectonic setting discrimination of sedimentary basins. Contributions to Mineralogy and Petrology, v. 92, p. 181-193, 1986.

BROD, J.A.; LEONARDOS, O.H.; MENESES, P.R.; ALMEIDA, R.; ARAÚJO, R.N.J.; BLANCO, S.B.; CARDOSO, F.B.F.; CARVALHO Jr., O.A.; JUNQUEIRA, F.F.; RIEHL Jr, W.; SOUZA, J.C.F.; TALLARICO, F.H.T.; THOMSEM, F.P.R.; ALBUQUERQUE, M.A.C.; BERBET, M.L.C.; CERQUEIRA, M.R.S.; CHAGAS, M.A.; DIAS, R.R.; LIMA, C.V.; NAKAMURA, E.T.; PORTO S,. G.; ROMÃO, P.A.; SANTOS, P.C.V. Tectono-estratigrafia da Faixa Brasília na região do Alto Paranaíba. In: Simpósio de Geologia do Centro-Oeste, III, Cuiabá, 1991. Anais... Cuiabá: Sociedade Brasileira de Geologia, v. 3, p. 155-168, 1991. 
BÜHN, B.; PIMENTEL, M.M.; MATTEINI, M.; DANTAS, E.L. High spatial resolution analysis of $\mathrm{Pb}$ and $\mathrm{U}$ isotopes for geochronology by laser ablation multi-collector inductively coupled plasma mass spectrometry (LA-MC-ICP-MS). Anais da Academia Brasileira de Ciências, v. 81, nº 1, p. 99-114, 2009.

CAMPO, M. \& GUEVARA, S.R. Provenance analysis and tectonic setting of late Neoproterozoic metasedimentary successions in NW Argentina. Journal of South American Earth Sciences, v. 19, p. 43-153, 2005.

CAMPOS NETO, M.C., BASEI, M.A.S., JANASI, V.A., MORAES, R. Orogen migration and tectonic setting of the Andrelândia Nappe system: An Ediacaran western Gondwana collage, south of São Francisco craton. Journal of South American Earth Sciences, v. 32, p. 393-406, 2011.

CULLERS, R.L. The geochemistry of shales, siltstones and sandstones of Pennsylvanian - Permian age, Colorado, USA: implications for provenance and metamorphic studies. Lithos, v. 51, p. 181-203, 2000.

CULLERS, R.L. Implications of elemental concentrations for provenance, redox conditions, and metamorphic studies of shales and limestones near Pueblo, CO, USA. Chemical Geology, v. 191, p. 305-327, 2002.

CULLERS, R.L.; YEH, L.T.; CHAUDHURI, S.; GUIDOTTI, C.V. Rare earth elements in Silurian pelitic schists from N.W. Maine. Geochimica et Cosmochimica Acta, v. 38, p. 389-400, 1974.

DARDENNE, M.A. The Brasília fold belt. In: U.G. Cordani, E.J. Milani, A. Thomaz Filho, D.A. Campos (Eds.), Tectonic Evolution of South America (231-264). Thirty-first International Geological Congress, Rio de Janeiro: Sociedade Brasileira de Geologia, 2000.

DE PAOLO, D.J. A neodymium ans strontium isotopic study of the Mesozoic calc-alkaline granitic batholiths of the Sierra Nevada and Peninsular Ranges, Califórnia. Journal of Geophysical Research, v. 86, p. 10470-10488, 1981.

DRAKE Jr., A.A. The Serra de Caldas windows. Tectonic Studies in the Brazilian shield. U. S. Geological Survev, Protessional Paper, 1999-A, B. p. A1 - A11, 1980.

ETEMAD-SAEED, N.; HOSSEINI-BARZI, M.; ARMSTRONGALTRIN, J.S. Petrography and geochemistry of clastic sedimentary rocks as evidence for provenance of the Lower Cambrian Lalun Formation, Posht-ebadam block, Central Iran. Journal of African Earth Sciences, v. 61, p. 142-159, 2011.

FATIMA, S. \& KHAN, M.S. Petrographic and geochemical characteristics of Mesoproterozoic Kumbalgarh clastic rocks, NW Indian shield: implications for provenance, tectonic setting, and crustal evolution. International Geology Review, v. 54, n. 10, p. 1113-1144, 2012.

FENG, R.; KERRICH, R.; MAAS, R. Geochemical, oxygen, and neodymium isotope compositions of metasediments from the Abitibi greenstone belt and Pontiac Subprovince, Canada: Evidence for ancient crust and Archean terrane juxtaposition. Geochimica et Cosmochimica Acta, v. 57, p. 641-658, 1993.

FLOYD, P.A., WINCHESTER, J.A., PARK, R. G. Geochemistry and Tectonic Setting of Lewisian Clastic Metasediments from the Early Proterozoic Loch Maree Group of Gairloch, NW Scotland. Precambrian Research, v. 45, p. 203-214, 1989.

FU, X.; WANG, J.; ZENG, Y.; TAN, F.; FENG, X. REE geochemistry of marine oil shale from the Changshe Mountain area, northern Tibet, China. International Journal of Coal Geology, v. 81, p. 191-199, 2010.

FUCK, R.A. Dobramentos neoproterozoicos da margem Ocidental do Cráton do São Francisco: revisão. In: CONGRESSO BRASILEIRO DE GEOLOGIA, XXXVI, Natal, 1990. Anais...Natal: Sociedade Brasileira de Geologia, 1990 , v. 1, 288-289.

FUCK, R.A. \& MARINI, O.J. O Grupo Araxá e unidades homotaxiais. In: SIMPÓSIO SOBRE O CRÁTON DO SÃO FRANCISCO E SUAS FAIXAS MARGINAIS, I, Salvador, 1981. Anais...Salvador: Sociedade Brasileira de Geologia, p. $118-130$.

GUO, Q.; XIAO, W.; WINDLEY, B. F.; MAO, Q.; HAN, C.;
QU, J.; AO, S.; LI, J.; SONG, D.; YONG, Y. Provenance and tectonic settings of Permian turbidites from the Beishan Mountains, NW China: implications for the Late Paleozoic accretionary tectonics of the Southern Altaids. Journal of Asian Earth Sciences, v. 49, p. 54-68, 2011.

HASUI, Y. Sistema Orogênico Tocantins. In: Y. Hasui, C.D.R. Carneiro, F.F.M. Almeida, A. Bartorelli (Eds.), Geologia do Brasil (289-325). São Paulo: Beca. 2012.

KLEIN, P.B.W. Geoquímica de rocha total, geocronologia de $\mathbf{U}$ $\mathrm{Pb}$ e geologia isotópica de $\mathrm{Sm}-\mathrm{Nd}$ das rochas ortognáissicas e unidades litológicas associadas da região de Ipameri - Catalão (Goiás). Brasília, 2008. Tese (Doutorado) - Instituto de Geociências, Universidade de Brasília. 2008.

LACERDA FILHO, J.V.; REZENDE, A.; SILVA, A. Programa de Levantamentos Geológicos Básicos do Brasil - Geologia e Recursos Minerais do Estado de Goiás e Distrito Federal. 1:500.000. $2^{\circ}$ edição. Goiânia: conv. CPRM - Superintendência Regional de Goiânia/METAGO S.A./UnB., 217 p., 1999.

MCLENNAN, S.M.; HEMMING, S.; MCDANIEL, D.K.; HANSON, G.N. Geochemical approaches to sedimentation, provenance, and tectonics. Geological Society of America, Special Paper, v. 284, p. 21-40, 1993.

MOREIRA, M.L.O.; MORETON, L.C.; ARAÚJO, V.A.; LACERDA FILHO, J.V.; COSTA, H.F. Geologia do Estado de Goiás e Distrito Federal. 1:500.000. Goiânia: CPRM/SIC - FUNMINERAL. Programa Geologia do Brasil: Integração, Atualização e Difusão de Dados de Geologia do Brasil. Programa Geologia e Mineração do Estado de Goiás: Geração e Disponibilização de Informações Geológicas e do Potencial Mineral de Goiás. 143 p., 2008.

NAVARRO, G.R.B.; MORAES, R.; ZANARDO, A.; SIMÕES, L.S.A.; CONCEIÇÃO, F.T. Trajetória $P-T$ e condições do metamorfismo usadas como ferramenta para a compartimentação tectônica da Faixa Brasília em Goiás. Revista Brasileira de Geociências, v. 39, n. 3, p. 544-559, 2009.

NAVARRO, G.R.B.; ZANARDO, A.; CONCEIÇÃO, F.T.; MORAES, R.; SIMÕES, L.S.A. Química Mineral e Estimativas de Pressão e Temperatura em Rochas Metassedimentares do Grupo Araxá na Região de Morrinhos, Sul do Estado de Goiás. Geologia USP, Série Científica, v. 11, n. 2, p. 3-20, 2011.

NAVARRO, G.R.B.; ZANARDO, A.; CONCEIÇÃO, F.T. Grupo Araxá em Goiás, um exemplo de bacia tipo fore arc neoproterozoica. In: CONGRESSO BRASILEIRO DE GEOLOGIA, XLVI, Santos, 2012. Anais...Santos: Sociedade Brasileira de Geologia, 2012

NAVARRO, G.R.B.; ZANARDO, A.; CONCEIÇÃO, F.T. O Grupo Araxá na Região Sul-Sudoeste do Estado de Goiás. Geologia USP, Série Científica, v. 13, n. 2, p. 5-28, 2013.

NAVARRO, G.R.B.; ZANARDO, A.; CONCEIÇÃO, F.T. Ortognaisses peraluminosos associados ao Grupo Araxá na região de Rochedo, Goiás. Geociências, v. 33, n. 4), p. 672-685, 2014.

PE-PIPER, G.; TRIANTAFYLLIDIS, S.; PIPER, D. J. W. Geochemical identification of clastic sediment provenance from known sources of similar geology: the Cretaceous Scotian Basin, Canada. Journal of Sedimentary Research, v. 78, p. 595-607, 2008.

PIMENTEL, M.M., FUCK, R.A., FISCHEL, D.P. Estudo isotópico Sm-Nd regional da porção central da Faixa Brasília: implicações para idade e origem dos granulitos do Complexo Anápolis-Itauçu e sedimentos do Grupo Araxá. Revista Brasileira de Geociências, v. 29, v. 2, p. 271-276, 1999.

PIMENTEL, M.M.; FUCK, R.A.; JOST, H.; FERREIRA FILHO, C.F.; ARAÚJO, S.D. The basament of the Brasília fold belt and the Goiás magmatic arc. In: U.G. Cordani, E.J. Milani, A. Thomaz Filho, D.A. Campos (Eds.), Tectonic Evolution of South America (195-229). Thirty-first International Geological Congress, Rio de Janeiro: Sociedade Brasileira de Geologia, 2000

PIMENTEL, M.M.; DARDENNE, M.A.; FUCK, R.A.; VIANA, M.G., JUNGES, S.L.; SEER, H.J.; FISCHEL, D.P. Nd isotopes 
and the provenance of sediments of the Neoproterozoic Brasília Belt, central Brazil. Journal of South American Earth Sciences, v. 14, p. 571-585, 2001.

PIMENTEL, M.M.; RODRIGUES, J.B.; DELLAGIUSTINA, M.E.S.; JUNGES, S.; MATTEINI, M.; ARMSTRONG, R. The tectonic evolution of the Neoproterozoic Brasília Belt, central Brazil, based on SHRIMP and LA-ICPMS U -Pb sedimentary provenance data: A review. Journal of South American Earth Sciences, v. 31, p. 34-357, 2011.

PIUZANA, D.; PIMENTEL, M.M.; FUCK, R. A.; ARMSTRONG, R. SHRIMP U-Pb and Sm-Nd data for the Araxá Group and associated magmatic rocks: constraints for the age of sedimentation and geodynamic context of the southern Brasília Belt, central Brazil. Precambrian Research, v. 125, p. 139-160, 2003.

RADAMBRASIL, Projeto. Folhas SF. 23/24 Rio de Janeiro/Vitória: geologia, geomorfologia, pedologia, vegetação e uso potencial da terra. Ministério das Minas e Energia, Rio de Janeiro, 1983, 780 p.

RAHMAN, M.J.J. \& SUZUKI, S. Geochemistry of sandstones from the Miocene Surma Group, Bengal Basin, Bangladesh: Implications for Provenance, tectonic setting and weathering. Geochemical Journal, v. 41, p. 415-428, 2007.

RAZA, M.; BHARDWAJ, V.R.; AHMAD, A.H.M.; MONDAL, M.E.A.; KHAN, A.; KHAN, M.S. Provenance and weathering history of Archaean Naharmagra quartzite of Aravalli craton, NW Indian Shield: Petrographic and geochemical evidence. Geochemical Journal, n. 44, p. 331-345, 2010.

RAZA, M.; AHMAD, A.H.M.; KHAN, M.S.; KHAN, F Geochemistry and detrital modes of Proterozoic sedimentary rocks, Bayana Basin, north Delhi fold belt: implications for provenance and source-area weathering. International Geology Review, v. 54, n. 1, p. 111-129, 2012.

ROSER, B. P.; COOPER, R.A.; NATHAN, S.; TULLOCH, A.J. Reconnaissance sandstone geochemistry, provenance, and tectonic setting of the Lower Paleozoic terranes of the West Coast and Nelson, New Zealand. New Zealand Journal of Geology and Geophysics, n. 39, p. 1-16, 1996.

RYAN, K.M. \& WILLIAMS, D.M. Testing the reliability of discrimination diagrams for determining the tectonic depositional environment of ancient sedimentar basins. Chemical Geology, v. 242, p. 103-125, 2007.

SANTOS, M.N.; CHEMALE JR., F.; DUSSIN, I.A.; MARTINS, M.S.; QUEIROGA, G.; PINTO, R.T.R.; SANTOS, A.N.; ARMSTRONG, R. Provenance and paleogeographic reconstruction of a mesoproterozoic intracratonic sag basin (Upper Espinhaço Basin, Brazil). Sedimentary Geology, v. 318, p. 40-57, 2015.

SELVARAJ, K. \& CHEN, C.T.A. Moderate chemical weathering of subtropical Taiwan: Constraints from solid-phase geochemistry of sediments and sedimentary rocks. The Journal of Geology, v. 114, v. 1, p. 101-116, 2006.

SIMÕES, L.S A. Compartimentos Crustais do Domínio Interno da Faixa Brasília no sul do estado de Goiás. Rio Claro, 2005. Tese (Livre Docência) - Instituto de Geociências e Ciências Exatas, Universidade Estadual Paulista.

SLACK, J.F. \& STEVENS, B.P.J. Clastic metasediments of the Early Proterozoic Broken Hill Group, New South Wales, Australia: Geochemistry, provenance, and metallogenic significance. Geochimica et Cosmochimica Acta, v. 58, p. 17 p. 3633-3652, 1994.

STRIEDER, A.J. \& NILSON, A.A. Melange ofiolítica nos metassedimentos Araxá de Abadiânia (GO) e implicações tectônicas regionais. Revista Brasileira de Geociências, v. 22, n. 2, p. 204-215, 1992.

TAYLOR, S.R. \& MCLENNAN, S.M. The composition and evolution of the continental crust: rare earth element evidence from sedimentary rocks. Philosophical Transactions of The
Royal Society, v. 301, p. 381-399, 1981

TAYLOR, S.R. \& MCLENNAN, S.M. The continental crust: its composition and evolution. Oxford: Blackwell Scientific Publications, 312p, 1985.

TRIPATHI, K.J. \& RAJAMANI, V. Geochemistry of Proterozoic Delhi quartzite: Implications for the provenance and source area weathering. Journal Geological Society of India, v. 62, p. 215-226, 2003.

TROUW, R.A.J., HEILBRON, M., RIBEIRO, A., PACIULLO, F.V.P., VALERIANO, C.M., ALMEIDA, J.C.H., TUPINAMBÁ, M., ANDREIS, R.R. The central segment of the Ribeira belt. In: U. G. Cordani, E. J. Milani, A. Thomaz Filho, D. A. Campos (Eds.), Tectonic Evolution of South America (287310). Thirty-first International Geological Congress, Rio de Janeiro: Sociedade Brasileira de Geologia, 2000.

UGARKAR, A.G. \& NYAMATI, R.C. Geochemical Characteristics of Archean Clastic Metasediments of Gadag Gold Field, Southern India: Implications for Provenance and Tectonic Setting. Gondwana Research, v. 5, n. 1, p. 245-255, 2001.

VALENTE, C.R. Projeto Mapas Metalogenéticos e de Previsão de Recursos Minerais - Folha Morrinhos, SE.22X-D. Brasília: DNPM/CPRM/SRG, 18 p, 1986.

VALERIANO, C.M.; MACHADO, N.; SIMONETTI, A.; VALLADARES, C.S.; SEER, H.J.; SIMÕES, L.S.A. U-Pb geochronology of the southern Brasília belt (SE-Brazil): sedimentary provenance, Neoproterozoic orogeny and assembly of West Gondwana. Precambrian Research, v. 130, p. 27-55, 2004.

VALERIANO, C.M.; MEDEIROS, S.R.; VAZ, G.S., NETO, C.C. Sm-Nd isotope dilution TIMS analyses of BCR-1, AGV1 and G-2 USGS rock reference materials: first results from the LAGIR Laboratory at UERJ, Rio de Janeiro. In: SIMPÓSIO 45 ANOS DE GEOCRONOLOGIA NO BRASIL, São Paulo, 2009. Atas...São Paulo: Sociedade Brasileira de Geologia, 2009, v. 1, 146-148.

VON EYNATTEN, H. \& DUNKL, I. Assessing the sediment factory: the role of single grain analysis. Earth-Science Reviews, v. 115, p. 97-120, 2012.

WELTJE, G.J. Quantitative models of sediment generation and provenance: state of the art and future developments. Sedimentary Geology, v. 280, p. 4-20, 2012.

WELTJE, G.J. Ternary sandstone composition and provenance: an evaluation of the Dickinson Model. In: A. Buccianti, G. Mateu-Figueras, V. Pawlowsky-Glahn (Eds.), Compositional Data Analysis in the Geosciences: From Theory to Practice (v. 264, 79-99, 2006), London: The Geological Society London, Special Publications.

WESTIN, A. \& CAMPOS NETO, M.C. Provenance and tectonic setting of the external nappe of the Southern Brasília Orogen. Journal of South American Earth Sciences, v. 48, p. 220239, 2013

ZAID, S.M. Provenance, diagenesis, tectonic setting and geochemistry of Rudies sandstone (Lower Miocene), Warda Field, Gulf of Suez, Egypt. Journal African Earth Science, v. 66-67, p. 56-71, 2012.

ZANARDO, A. Análise petrográfica, estratigráfica e microestrutural da região de Guaxupé-Passos-Delfinópolis (MG). Rio Claro, 1992. 288p. Tese (Doutorado) - Instituto de Geociências e Ciências Exatas, Universidade Estadual Paulista (UNESP).

ZANARDO, A.; OLIVEIRA, M.A.F.; DEL LAMA, E.A.; CARVALHO, S.G. Geologia do Grupo Araxá de Passos-São Sebastião do Paraíso, sul de Minas Gerais. Geociências, v. 15, n. 1, p. 253-278, 1996.

Submetido em 06 de outubro de 2017 Aceito em 20 de setembro de 2019 


\section{APÊNDICE}

Tabela 1. Teores de elementos maiores (em \%), elementos traço (em ppm) e ETR (em ppm) das amostras analisadas.

\begin{tabular}{|c|c|c|c|c|c|c|c|c|c|}
\hline Amostra & A5 & A54 & A55 & A71 & A73 & A75 & A109 & A112 & A114 \\
\hline $\mathrm{SiO}_{2}$ & 62,5 & 65,13 & 64,45 & 64,28 & 69,54 & 72,53 & 66,11 & 62,81 & 58,29 \\
\hline $\mathrm{TiO}_{2}$ & 0,87 & 0,77 & 0,81 & 0,62 & 1 & 0,52 & 1 & 0,77 & 1,1 \\
\hline $\mathrm{Al}_{2} \mathrm{O}_{3}$ & 15,54 & 14,75 & 15,12 & 13,74 & 12,7 & 12,93 & 15,08 & 15,54 & 18,76 \\
\hline $\mathrm{Fe}_{2} \mathrm{O}_{3} \mathrm{~T}$ & 7,18 & 6,52 & 6,75 & 5,38 & 6,67 & 4,29 & 6,91 & 7,96 & 10,22 \\
\hline MnO & 0,11 & 0,15 & 0,11 & 0,11 & 0,12 & 0,06 & 0,1 & 0,14 & 0,17 \\
\hline MgO & 3,46 & 3,28 & 3,38 & 2,15 & 2,13 & 1,2 & 2,32 & 2,47 & 3,07 \\
\hline $\mathrm{CaO}$ & 1,94 & 2,12 & 2,12 & 3,07 & 1,75 & 0,1 & 0,79 & 5,1 & 1,01 \\
\hline $\mathrm{Na}_{2} \mathrm{O}$ & 2,59 & 2,94 & 2,97 & 1,16 & 1,81 & 0,07 & 1,2 & 2,58 & 1,46 \\
\hline $\mathbf{K}_{2} \mathbf{O}$ & 3,25 & 2,05 & 2,23 & 4,23 & 2,62 & 4,79 & 3,51 & 1,76 & 4,24 \\
\hline $\mathbf{P}_{2} \mathrm{O}_{5}$ & 0,2 & 0,18 & 0,18 & 0,12 & 0,15 & 0,12 & 0,17 & 0,1 & 0,16 \\
\hline LOI & 2,1 & 1,9 & 1,6 & 4,9 & 1,3 & 3,2 & 2,6 & 0,6 & 1,3 \\
\hline Total & 99,75 & 99,78 & 99,78 & 99,77 & 99,79 & 99,78 & 99,79 & 99,83 & 99,75 \\
\hline Sc & 16 & 16 & 17 & 12 & 15 & 8 & 16 & 22 & 23 \\
\hline $\mathbf{V}$ & 113 & 132 & 146 & 63 & 114 & 58 & 118 & 136 & 159 \\
\hline $\mathrm{Cr}$ & 102,63 & 130,00 & 116,31 & 109,47 & 136,84 & 82,10 & 88,94 & 54,73 & 116,31 \\
\hline Co & 20,5 & 19,4 & 19 & 13,7 & 15,9 & 7,7 & 19,7 & 17,1 & 26,6 \\
\hline $\mathbf{N i}$ & 53,1 & 50,4 & 54,1 & 25,3 & 42,4 & 10,4 & 42,1 & 12,7 & 61,2 \\
\hline $\mathrm{Cu}$ & 21,7 & 34,9 & 46,2 & 0,8 & 14,7 & 25,7 & 57,1 & 16,2 & 57,9 \\
\hline $\mathbf{Z n}$ & 88 & 84 & 84 & 46 & 87 & 40 & 77 & 66 & 109 \\
\hline $\mathbf{R b}$ & 131,8 & 66,2 & 79,6 & 169,2 & 95,1 & 249,7 & 125,9 & 114,5 & 176,3 \\
\hline Cs & 9,1 & 4,4 & 5,4 & 7 & 5,3 & 7,1 & 7,1 & 7,9 & 8,9 \\
\hline $\mathrm{Sr}$ & 217,1 & 213,2 & 229,2 & 58,1 & 123 & 25,5 & 111,8 & 173,4 & 105,4 \\
\hline $\mathbf{B a}$ & 647 & 491 & 485 & 1084 & 533 & 602 & 627 & 280 & 676 \\
\hline Y & 29 & 28,8 & 30,8 & 23,4 & 35,1 & 124,3 & 32,5 & 23,9 & 40,5 \\
\hline $\mathbf{Z r}$ & 175,2 & 172,4 & 177,6 & 162,5 & 282,5 & 211,5 & 205,7 & 173,8 & 198 \\
\hline Hf & 4,8 & 4,6 & 4,8 & 4,7 & 7,2 & 6 & 6 & 4,6 & 5,6 \\
\hline $\mathrm{Nb}$ & 15,1 & 8,3 & 8,3 & 12,4 & 14,8 & 11,4 & 15,5 & 10,8 & 15,9 \\
\hline $\mathbf{T a}$ & 1,1 & 0,7 & 0,6 & 1 & 1,1 & 0,8 & 1,1 & 0,8 & 1,2 \\
\hline $\mathbf{P b}$ & 2,5 & 1,7 & 2 & 4,9 & 2,2 & 13,4 & 3,5 & 1,3 & 3,1 \\
\hline Th & 9,8 & 6,3 & 6 & 12,5 & 10,7 & 15 & 12,1 & 3,4 & 14,1 \\
\hline $\mathbf{U}$ & 2 & 2 & 1,5 & 1,6 & 2,7 & 1,9 & 2,3 & 1,1 & 2,5 \\
\hline $\mathbf{G a}$ & 19,3 & 17 & 17,3 & 16,8 & 14,8 & 17,9 & 19,2 & 19,2 & 25,8 \\
\hline La & 38,5 & 27,6 & 28 & 36,3 & 35,3 & 93,4 & 45,1 & 19,6 & 49,2 \\
\hline $\mathrm{Ce}$ & 74,9 & 54,5 & 57 & 71,5 & 68,7 & 195,1 & 80,5 & 39 & 91,7 \\
\hline Pr & 8,58 & 6,57 & 6,95 & 7,71 & 8,11 & 23,46 & 10,59 & 5,44 & 11,32 \\
\hline Nd & 33,7 & 27 & 28,3 & 28,4 & 31,6 & 100,4 & 39,6 & 21 & 42,5 \\
\hline Sm & 6,48 & 5,51 & 6,19 & 5,15 & 6,7 & 20,47 & 7,7 & 4,64 & 8,42 \\
\hline Eu & 1,39 & 1,31 & 1,42 & 1 & 1,35 & 3,1 & 1,67 & 1,16 & 1,67 \\
\hline Gd & 6,13 & 5,46 & 5,89 & 4,44 & 6,31 & 23,97 & 7,27 & 4,61 & 7,54 \\
\hline $\mathbf{T b}$ & 0,95 & 0,87 & 0,93 & 0,71 & 1,01 & 3,71 & 1,16 & 0,77 & 1,23 \\
\hline Dy & 5,32 & 4,86 & 5,3 & 4,18 & 5,98 & 21,06 & 6,53 & 4,33 & 7,39 \\
\hline Ho & 1,03 & 1,07 & 1,18 & 0,89 & 1,26 & 4,12 & 1,17 & 0,83 & 1,38 \\
\hline $\mathbf{E r}$ & 2,81 & 3,12 & 3,17 & 2,64 & 3,71 & 11,62 & 3,49 & 2,66 & 4,27 \\
\hline Tm & 0,44 & 0,47 & 0,5 & 0,4 & 0,59 & 1,68 & 0,5 & 0,37 & 0,59 \\
\hline $\mathbf{Y b}$ & 2,77 & 2,93 & 3,25 & 2,61 & 3,85 & 10,01 & 3,21 & 2,41 & 3,82 \\
\hline Lu & 0,41 & 0,48 & 0,48 & 0,4 & 0,6 & 1,45 & 0,47 & 0,38 & 0,59 \\
\hline EETR & 183,41 & 141,75 & 148,56 & 166,33 & 175,07 & 513,55 & 208,96 & 107,2 & 231,62 \\
\hline 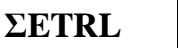 & 163,55 & 122,49 & 127,86 & 150,06 & 151,76 & 435,93 & 185,16 & 90,84 & 204,81 \\
\hline 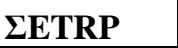 & 19,86 & 19,26 & 20,7 & 16,27 & 23,31 & 77,62 & 23,8 & 16,36 & 26,81 \\
\hline $\mathbf{L a}(\mathbf{N}) / \mathbf{E} \mathbf{u}_{(\mathbf{N})}$ & 6,77 & 5,15 & 4,82 & 8,88 & 6,39 & 7,37 & 6,60 & 4,13 & 7,20 \\
\hline $\mathbf{G d}_{(\mathbf{N})} / \mathbf{L} \mathbf{u}_{(\mathbf{N})}$ & 1,86 & 1,41 & 1,52 & 1,38 & 1,31 & 2,05 & 1,92 & 1,51 & 1,59 \\
\hline $\mathbf{L} \mathbf{a}_{(\mathrm{N})} / \mathbf{L} \mathbf{u}_{(\mathbf{N})}$ & 10,11 & 6,19 & 6,28 & 9,78 & 6,34 & 6,94 & 10,34 & 5,56 & 8,98 \\
\hline Eu* & 0,67 & 0,72 & 0,71 & 0,62 & 0,63 & 0,43 & 0,67 & 0,76 & 0,63 \\
\hline La/Sc & 2,41 & 1,73 & 1,65 & 3,03 & 2,35 & 11,68 & 2,82 & 0,89 & 2,14 \\
\hline Th/Sc & 0,61 & 0,39 & 0,35 & 1,04 & 0,71 & 1,88 & 0,76 & 0,15 & 0,61 \\
\hline $\mathrm{La} / \mathrm{Co}$ & 1,88 & 1,42 & 1,47 & 2,65 & 2,22 & 12,13 & 2,29 & 1,15 & 1,85 \\
\hline Th/Co & 0,48 & 0,32 & 0,32 & 0,91 & 0,67 & 1,95 & 0,61 & 0,20 & 0,53 \\
\hline $\mathrm{Cr} / \mathrm{Th}$ & 10,47 & 20,63 & 19,39 & 8,76 & 12,79 & 5,47 & 7,35 & 16,10 & 8,25 \\
\hline
\end{tabular}


Tabela 1. Teores de elementos maiores (em \%), elementos traço (em ppm) e ETR (em ppm) das amostras analisadas (continuação)

\begin{tabular}{|c|c|c|c|c|c|c|c|c|}
\hline Amostra & A115 & 2009-0* & 2009-35* & 2009-36* & 2009-59* & 2009-60* & 2009-61* & $2009-62 *$ \\
\hline $\mathrm{SiO}_{2}$ & 64,04 & 61,94 & 66,91 & 64,11 & 66,45 & 68,39 & 63,15 & 62,96 \\
\hline $\mathrm{TiO}_{2}$ & 0,82 & 0,85 & 0,98 & 0,82 & 0,95 & 0,9 & 1,07 & 0,86 \\
\hline $\mathrm{Al}_{2} \mathrm{O}_{3}$ & 15,33 & 16,16 & 13,89 & 15,08 & 15,23 & 14,03 & 15,55 & 16,89 \\
\hline $\mathrm{Fe}_{2} \mathrm{O}_{3} \mathrm{~T}$ & 6,96 & 7,85 & 6,9 & 6,76 & 7,56 & 6,83 & 8,94 & 7,54 \\
\hline MnO & 0,13 & 0,13 & 0,12 & 0,12 & 0,13 & 0,11 & 0,11 & 0,11 \\
\hline MgO & 3,49 & 3,65 & 2,89 & 3,18 & 2,16 & 2,33 & 3,66 & 2,9 \\
\hline $\mathrm{CaO}$ & 2,8 & 3,05 & 3,77 & 4,85 & 1,08 & 1,59 & 0,84 & 0,94 \\
\hline $\mathrm{Na}_{2} \mathrm{O}$ & 2,67 & 2,78 & 2,15 & 3,18 & 1,94 & 2,02 & 0,6 & 1,29 \\
\hline $\mathrm{K}_{2} \mathrm{O}$ & 2,53 & 2,53 & 1,51 & 1,2 & 3,17 & 2,67 & 2,77 & 4,06 \\
\hline $\mathrm{P}_{2} \mathrm{O}_{5}$ & 0,18 & 0,21 & 0,19 & 0,2 & 0,17 & 0,15 & 0,07 & 0,19 \\
\hline LOI & 0,8 & 0,6 & 0,5 & 0,3 & 1 & 0,8 & 2,9 & 2 \\
\hline Total & 99,78 & 99,75 & 99,82 & 99,81 & 99,81 & 99,8 & 99,7 & 99,74 \\
\hline Sc & 17 & 20 & 18 & 18 & 18 & 16 & 22 & 20 \\
\hline $\mathbf{V}$ & 145 & 159 & 137 & 126 & 124 & 123 & 129 & 144 \\
\hline $\mathrm{Cr}$ & 116,31 & 109,47 & 205,26 & 116,31 & 88,94 & 82,10 & 75,26 & 95,79 \\
\hline Co & 19,8 & 21,4 & 16,2 & 17,8 & 20,4 & 19,8 & 19,5 & 59,2 \\
\hline $\mathrm{Ni}$ & 60,2 & 69,7 & 46,8 & 41,4 & 45 & 45,4 & 25,6 & 72,8 \\
\hline $\mathrm{Cu}$ & 36,5 & 42,4 & 30,5 & 14 & 33,1 & 52,5 & 1,5 & 43,6 \\
\hline $\mathbf{Z n}$ & 91 & 100 & 69 & 50 & 79 & 78 & 87 & 106 \\
\hline $\mathbf{R b}$ & 83,4 & 77,8 & 38,5 & 34,1 & 131,1 & 108,7 & 67,9 & 147,7 \\
\hline Cs & 5,2 & 4,4 & 2,2 & 1,3 & 7,3 & 6,3 & 3,1 & 7,1 \\
\hline $\mathbf{S r}$ & 194,7 & 222,2 & 205,3 & 305,6 & 115,8 & 126,7 & 115,8 & 131,7 \\
\hline $\mathbf{B a}$ & 514 & 530 & 306 & 419 & 500 & 519 & 1039 & 712 \\
\hline $\mathbf{Y}$ & 28,9 & 29,2 & 28,7 & 29 & 30,3 & 28,8 & 29,3 & 33,2 \\
\hline $\mathbf{Z r}$ & 176,5 & 169,1 & 218,7 & 156,9 & 222,4 & 229,9 & 278,5 & 199 \\
\hline Hf & 4,8 & 5,4 & 6,7 & 4,4 & 6,5 & 6,6 & 7,8 & 5,9 \\
\hline $\mathbf{N b}$ & 8,4 & 9,7 & 9,1 & 7,5 & 15,9 & 13,4 & 18,5 & 13,4 \\
\hline $\mathbf{T a}$ & 0,5 & 0,7 & 0,5 & 0,6 & 1,1 & 0,9 & 1,3 & 1 \\
\hline $\mathbf{P b}$ & 1,6 & 1,8 & 1,8 & 1,3 & 2,8 & 2,2 & 4,1 & 4 \\
\hline Th & 5,9 & 7,3 & 6,8 & 6,2 & 13,5 & 10,6 & 15,1 & 12,1 \\
\hline $\mathbf{U}$ & 1,7 & 2 & 1,9 & 2 & 2,3 & 1,7 & 1,5 & 3,2 \\
\hline $\mathbf{G a}$ & 18,4 & 18,8 & 14,3 & 15,9 & 19 & 18,2 & 21,4 & 22,4 \\
\hline La & 32,5 & 20,2 & 23,4 & 22 & 36,5 & 31,5 & 68,3 & 33,9 \\
\hline $\mathrm{Ce}$ & 58,9 & 47,7 & 49,6 & 47 & 78,6 & 72,4 & 138,1 & 73,6 \\
\hline Pr & 7,6 & 5,88 & 6,28 & 6,11 & 8,83 & 7,79 & 16,22 & 8,35 \\
\hline Nd & 30,2 & 23,9 & 27 & 25,6 & 33 & 31,5 & 62,7 & 33,5 \\
\hline Sm & 6,31 & 5,1 & 5,16 & 5,18 & 6,23 & 5,83 & 10,32 & 6,3 \\
\hline Eu & 1,37 & 1,28 & 1,28 & 1,35 & 1,35 & 1,26 & 2,45 & 1,32 \\
\hline Gd & 6,16 & 4,79 & 4,98 & 5,15 & 5,47 & 5,1 & 8,26 & 5,63 \\
\hline $\mathbf{T b}$ & 0,96 & 0,9 & 0,84 & 0,86 & 0,95 & 0,93 & 1,24 & 0,97 \\
\hline Dy & 5,37 & 5,39 & 4,66 & 4,83 & 5,28 & 5,16 & 5,78 & 5,7 \\
\hline Но & 1,02 & 1,1 & 0,99 & 0,95 & 1,06 & 1,04 & 1,08 & 1,13 \\
\hline $\mathbf{E r}$ & 2,97 & 3,13 & 3,01 & 2,75 & 3,21 & 2,95 & 3 & 3,31 \\
\hline $\mathbf{T m}$ & 0,45 & 0,51 & 0,49 & 0,42 & 0,49 & 0,47 & 0,47 & 0,51 \\
\hline Yb & 3,1 & 3,2 & 3,07 & 2,6 & 3,14 & 3,05 & 3,16 & 3,29 \\
\hline Lu & 0,44 & 0,47 & 0,48 & 0,4 & 0,49 & 0,45 & 0,52 & 0,52 \\
\hline EETR & 157,35 & 123,55 & 131,24 & 125,2 & 184,6 & 169,43 & 321,6 & 178,03 \\
\hline इETRL & 136,88 & 104,06 & 112,72 & 107,24 & 164,51 & 150,28 & 298,09 & 156,97 \\
\hline 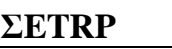 & 20,47 & 19,49 & 18,52 & 17,96 & 20,09 & 19,15 & 23,51 & 21,06 \\
\hline $\mathbf{L} \mathbf{a}_{(\mathrm{N})} / \mathbf{E} \mathbf{u}_{(\mathrm{N})}$ & 5,80 & 3,86 & 4,47 & 3,99 & 6,61 & 6,11 & 6,82 & 6,28 \\
\hline $\mathbf{G d}_{(\mathrm{N})} / \mathbf{L u}_{(\mathrm{N})}$ & 1,74 & 1,27 & 1,29 & 1,60 & 1,39 & 1,41 & 1,97 & 1,34 \\
\hline $\mathbf{L} \mathbf{a}_{(\mathrm{N})} / \mathbf{L} \mathbf{u}_{(\mathrm{N})}$ & 7,96 & 4,63 & 5,25 & 5,92 & 8,02 & 7,54 & 14,15 & 7,02 \\
\hline $\mathbf{E u} *$ & 0,66 & 0,78 & 0,76 & 0,79 & 0,69 & 0,69 & 0,79 & 0,66 \\
\hline $\mathbf{L a} / \mathrm{Sc}$ & 1,91 & 1,01 & 1,30 & 1,22 & 2,03 & 1,97 & 3,10 & 1,69 \\
\hline Th/Sc & 0,35 & 0,37 & 0,38 & 0,34 & 0,75 & 0,66 & 0,69 & 0,60 \\
\hline $\mathrm{La} / \mathrm{Co}$ & 1,64 & 0,94 & 1,44 & 1,24 & 1,79 & 1,59 & 3,50 & 0,57 \\
\hline Th/Co & 0,30 & 0,34 & 0,42 & 0,35 & 0,66 & 0,54 & 0,77 & 0,20 \\
\hline $\mathrm{Cr} / \mathrm{Th}$ & 19,71 & 15,00 & 30,19 & 18,76 & 6,59 & 7,75 & 4,98 & 7,91 \\
\hline
\end{tabular}


Tabela 2. Resultados das análises $\mathrm{Sm} / \mathrm{Nd}$ em rocha total de rochas metassedimentares do Grupo Araxá.

\begin{tabular}{c|c|c|c|c|c|c|c}
\hline & $\mathbf{S m}(\mathbf{p p m})$ & $\mathbf{N d}(\mathbf{p p m})$ & ${ }^{\mathbf{1 4 3}} \mathbf{N d} / \mathbf{1 4 4}^{\mathbf{4 4}} \mathbf{N}$ & $\mathbf{( \mathbf { 2 S E } )}$ & ${ }^{\mathbf{1 4 7}} \mathbf{N d} /{ }^{\mathbf{1 4 4}} \mathbf{N d}$ & $\mathbf{\varepsilon N d}(\mathbf{0})$ & $\mathbf{T D M}$ \\
\hline $\mathbf{2 0 1 4 - 5}$ & 6,4 & 32,0 & 0,512167 & 0,000005 & 0,1215 & $-9,2$ & 1,39 \\
\hline $\mathbf{2 0 1 5 - 5 4}$ & 5,3 & 24,7 & 0,512350 & 0,000007 & 0,1296 & $-5,6$ & 1,21 \\
\hline $\mathbf{2 0 1 5 - 5 5}$ & 7,0 & 31,5 & 0,512362 & 0,000007 & 0,1339 & $-5,4$ & 1,25 \\
\hline $\mathbf{2 0 1 5 - 7 3}$ & 6,0 & 28,8 & 0,512227 & 0,000006 & 0,1261 & $-8,0$ & 1,36 \\
\hline $\mathbf{2 0 1 5 - 1 0 9}$ & 8,1 & 39,1 & 0,511978 & 0,000005 & 0,13 & $-12,9$ & 1,74 \\
\hline $\mathbf{2 0 1 5 - 1 1 5}$ & 6,2 & 27,5 & 0,512374 & 0,000008 & 0,14 & $-5,2$ & 1,27 \\
\hline
\end{tabular}


Tabela 3. Resultados das análises U/Pb (LA-ICP-MS) em cristais de zircão das amostras A54, A73, A109 e A115.

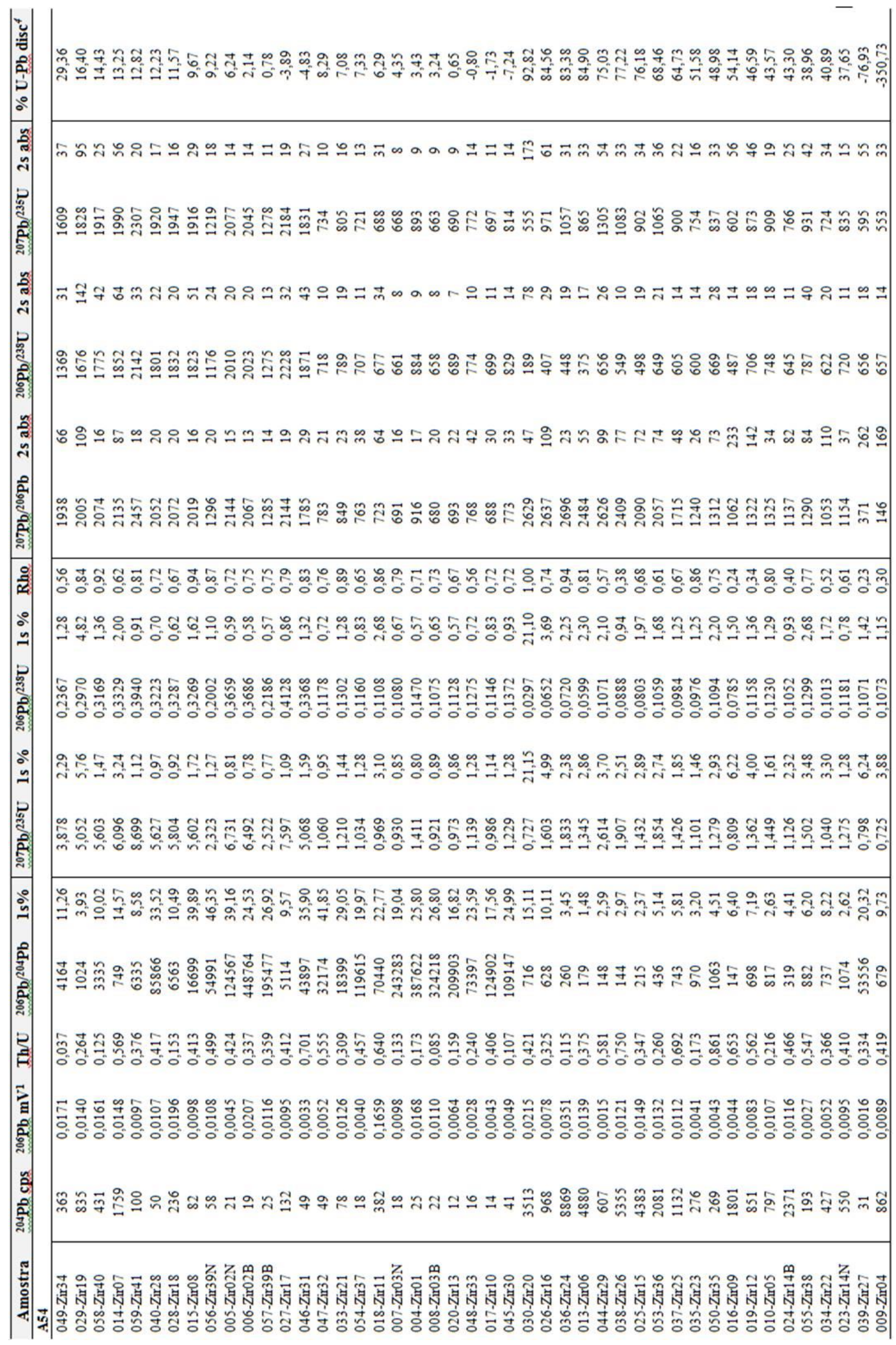


Tabela 3. Resultados das análises U/Pb (LA-ICP-MS) em cristais de zircão das amostras A54, A73, A109 e A115 (cont.)

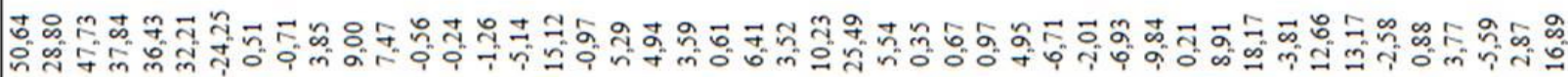

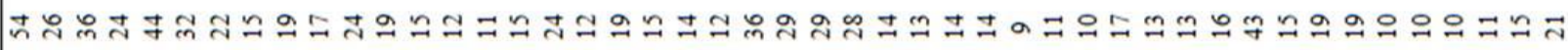

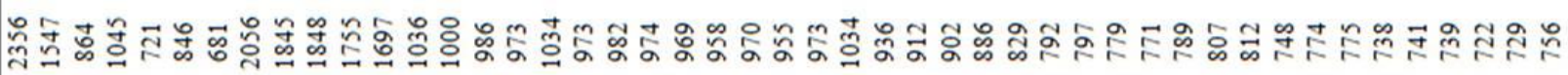

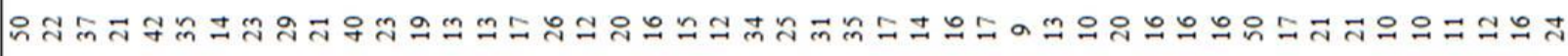

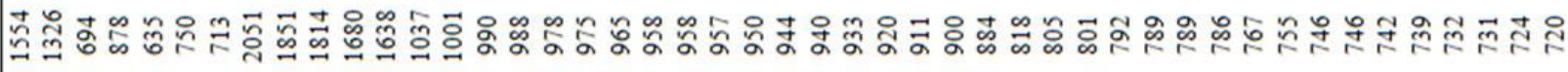

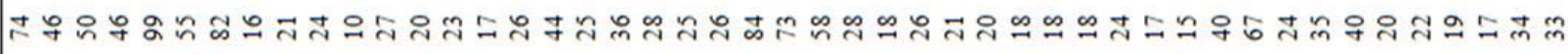

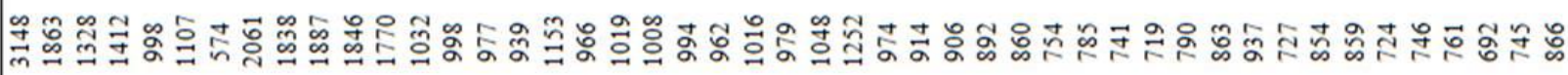

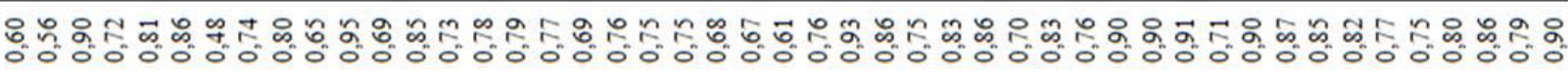

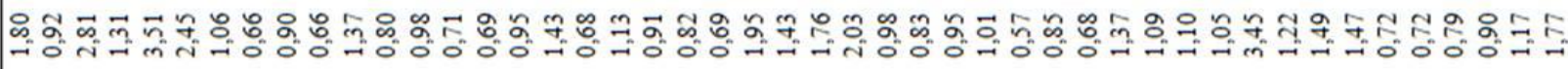

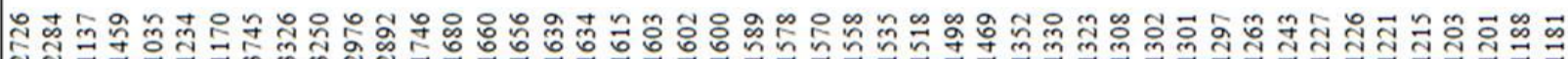

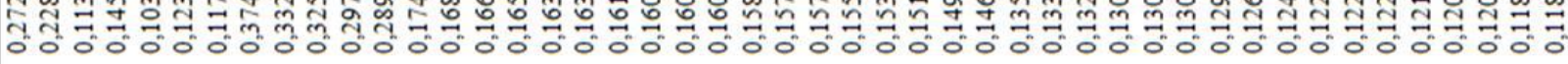

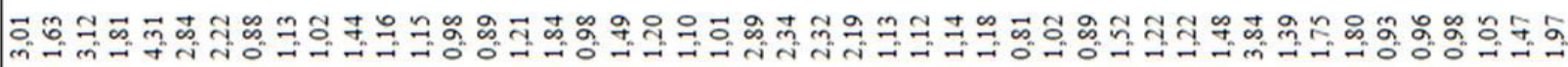

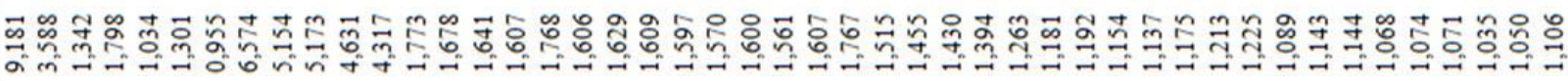

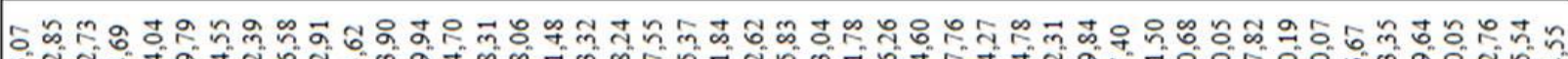

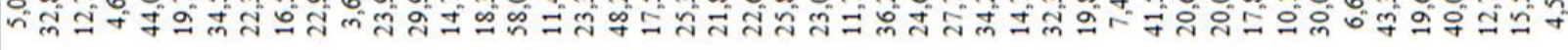

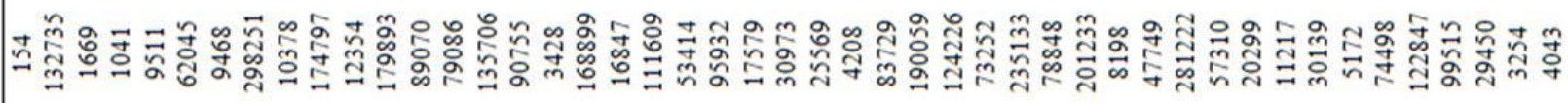

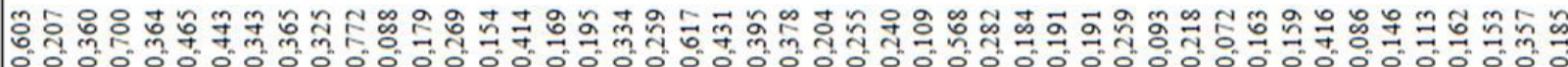

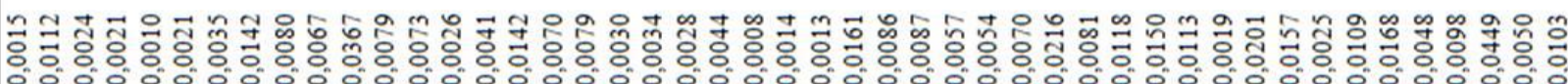

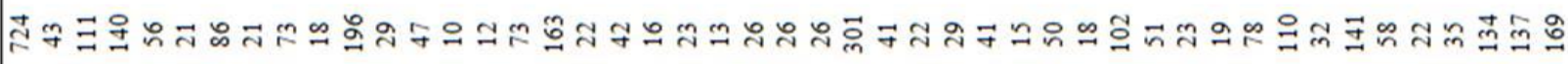

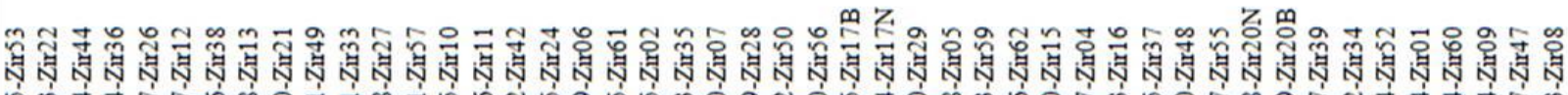

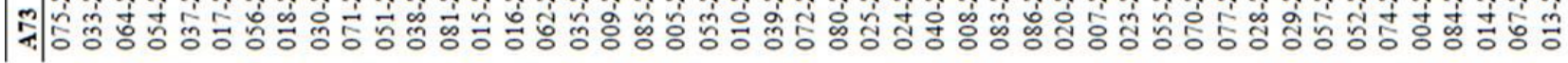


Tabela 3. Resultados das análises U/Pb (LA-ICP-MS) em cristais de zircão das amostras A54, A73, A109 e A115 (cont.)

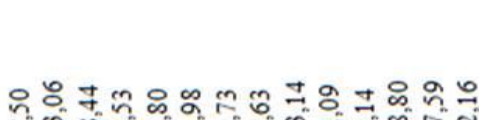

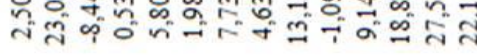

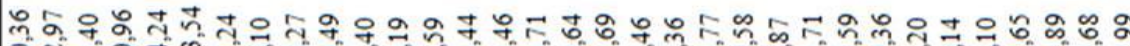

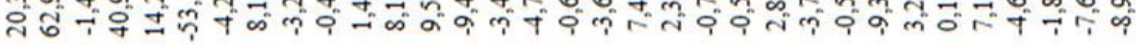

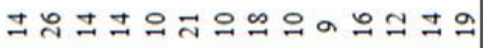

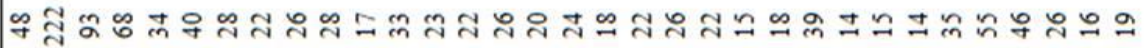

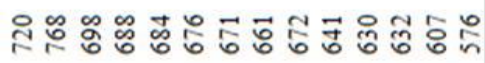

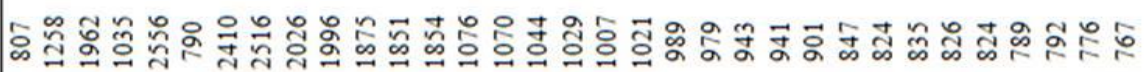

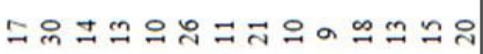

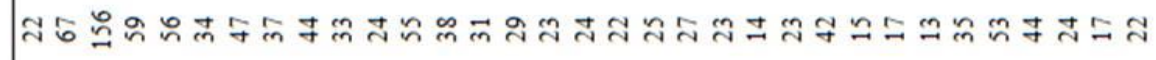

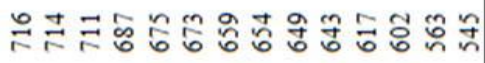

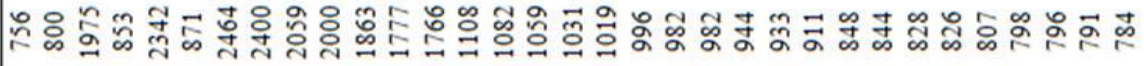

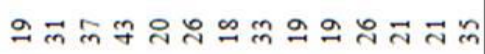

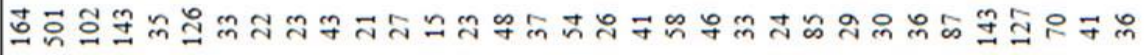

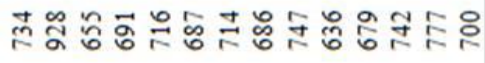

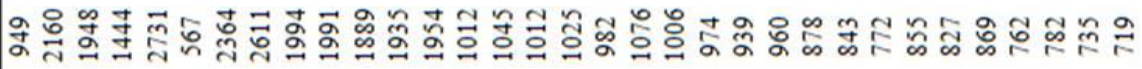

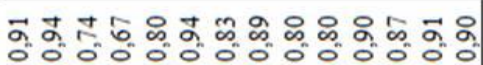

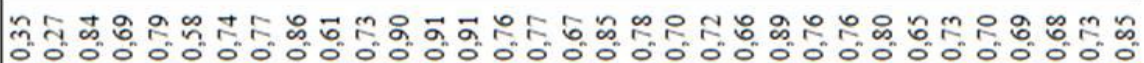

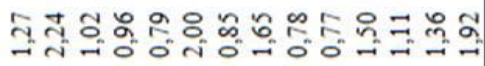

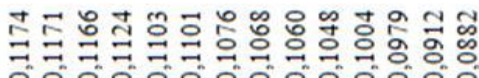

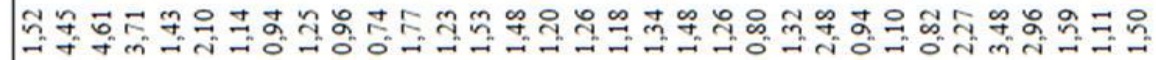

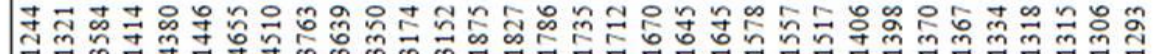

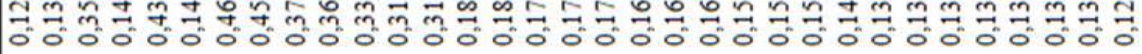

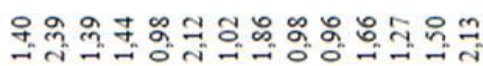

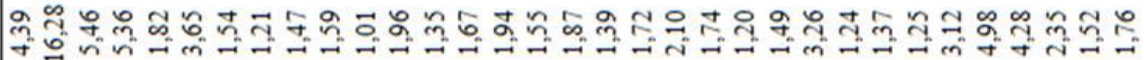

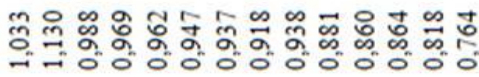

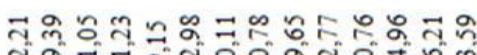

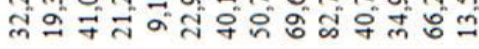

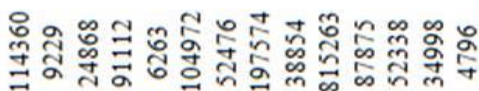

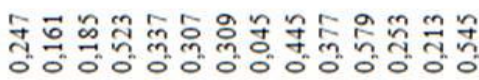

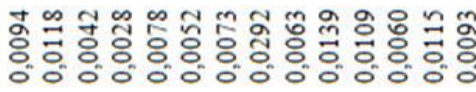

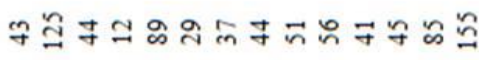

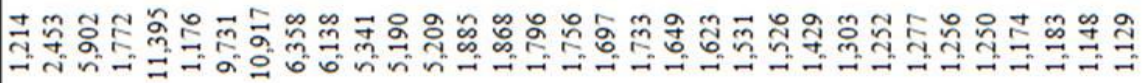

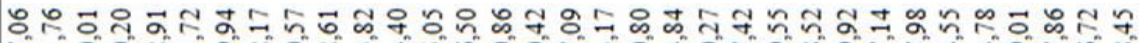

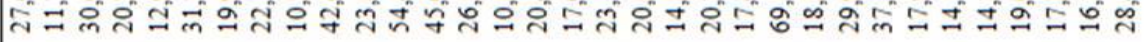

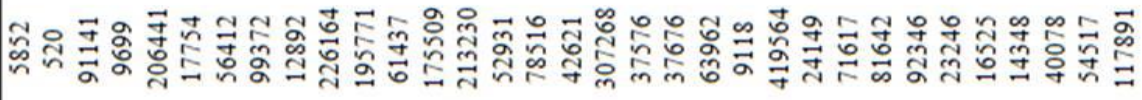

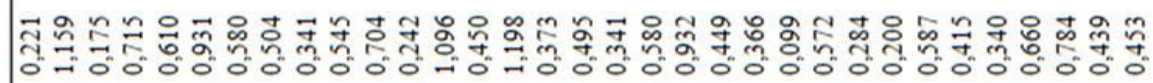

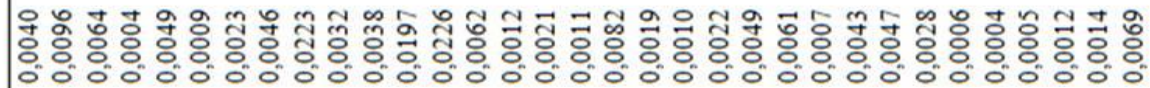

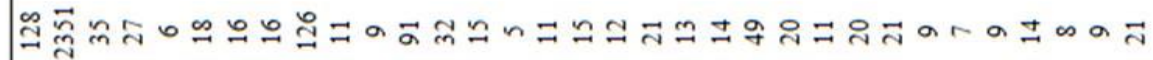

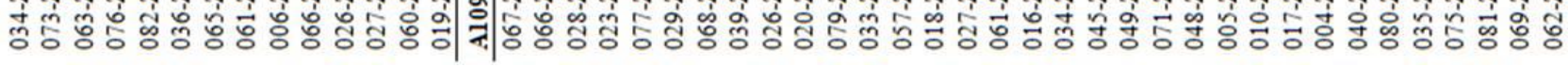


Tabela 3. Resultados das análises U/Pb (LA-ICP-MS) em cristais de zircão das amostras A54, A73, A109 e A115 (cont.)

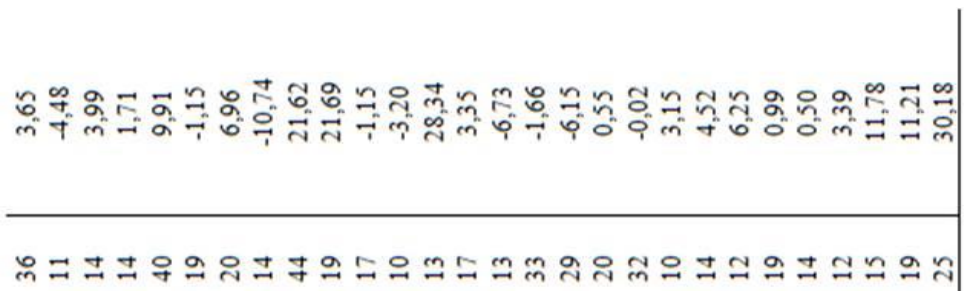

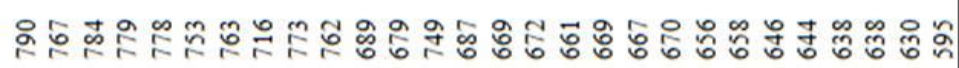

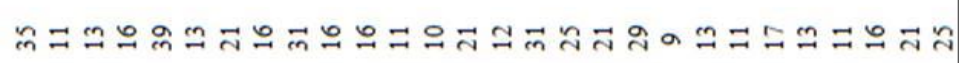

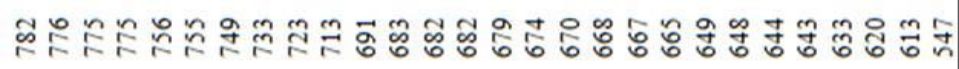

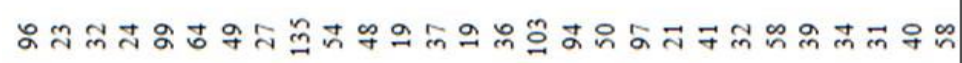

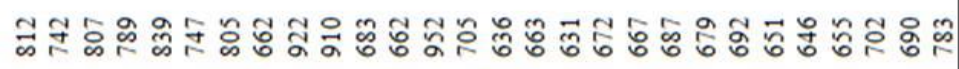

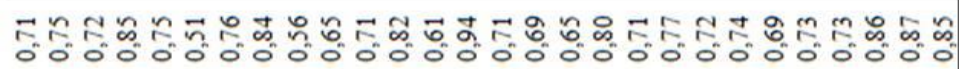

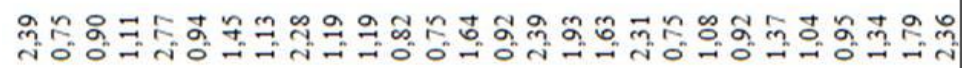

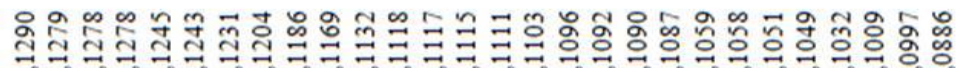

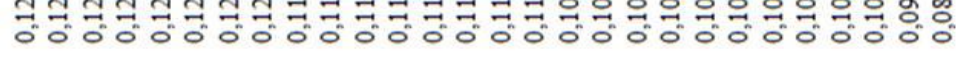

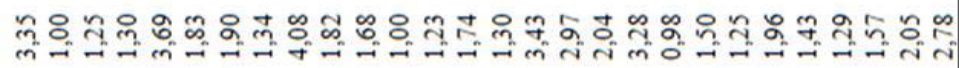

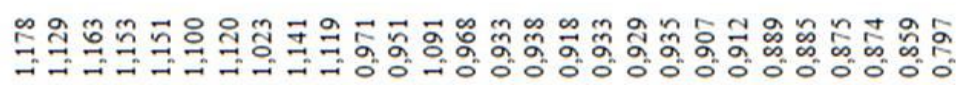

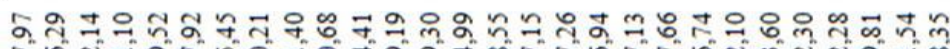

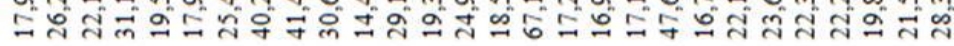

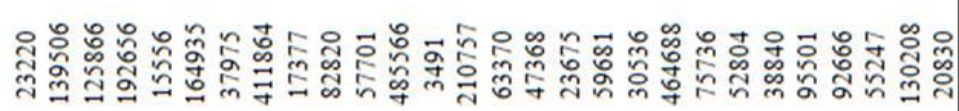

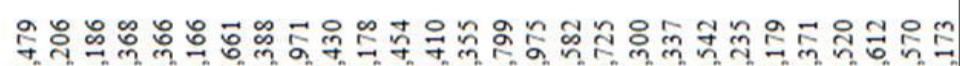

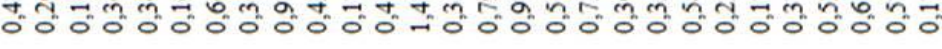

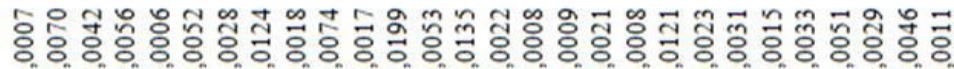

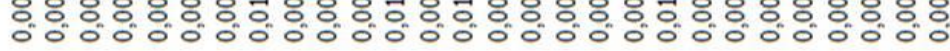

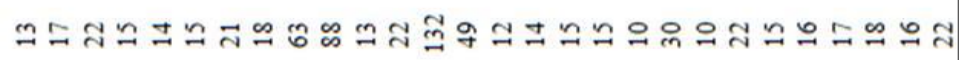
드를

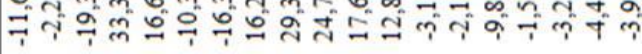

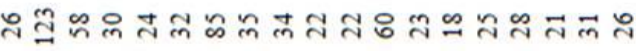

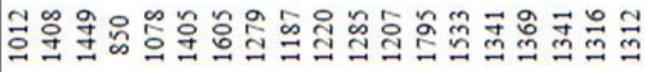

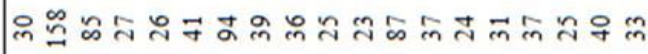

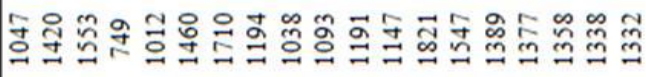
๓ํㅠ엉ㅇำ

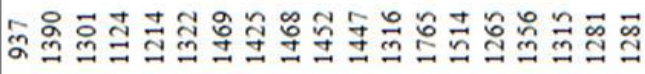

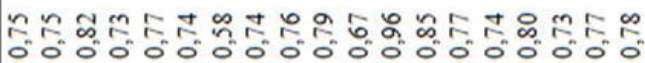

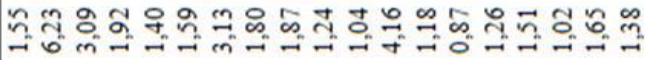

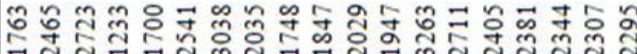

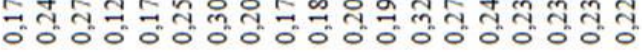

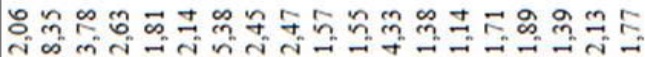

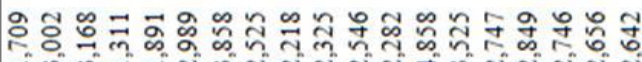

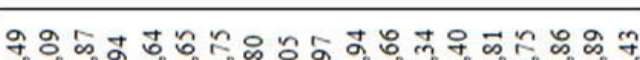
年

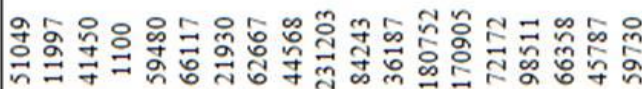

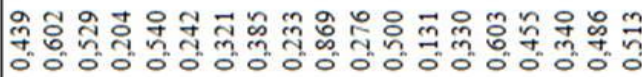

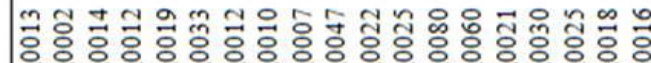

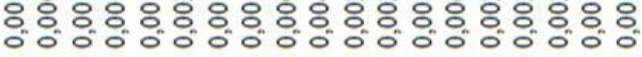

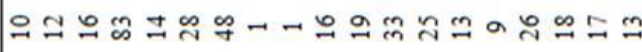

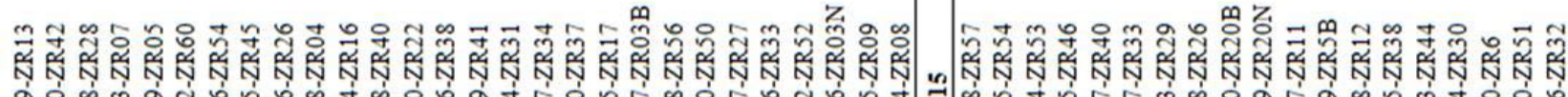

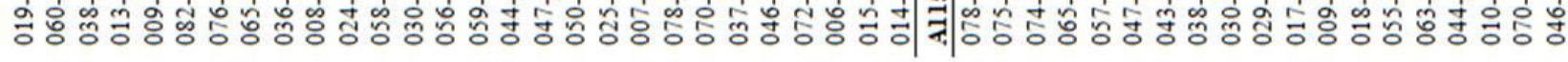


Tabela 3. Resultados das análises U/Pb (LA-ICP-MS) em cristais de zircão das amostras A54, A73, A109 e A115 (cont.)

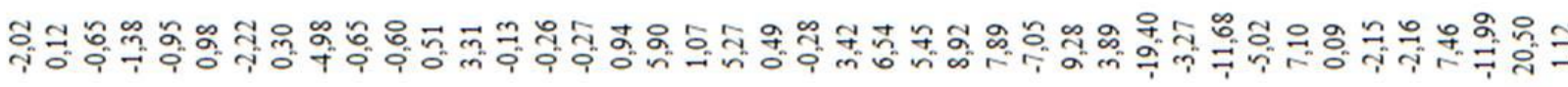

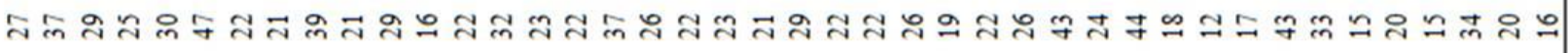

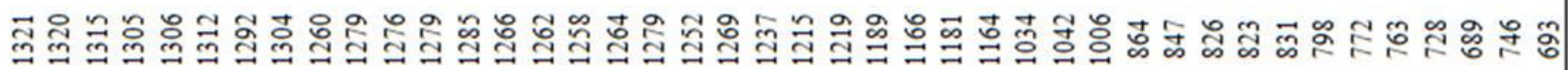

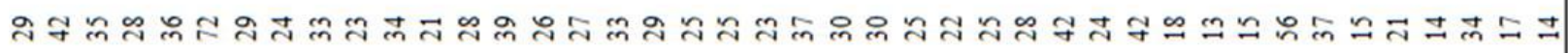

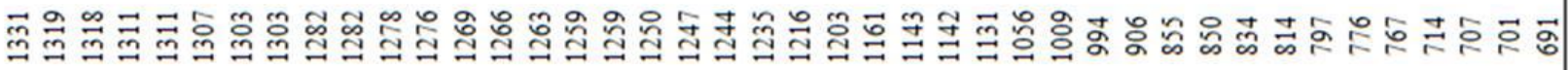

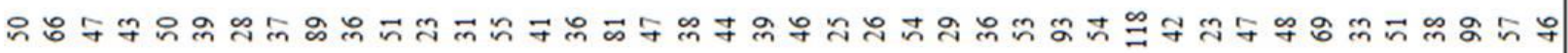

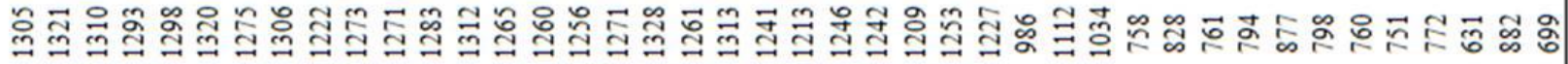

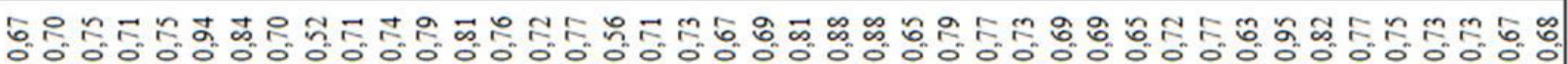

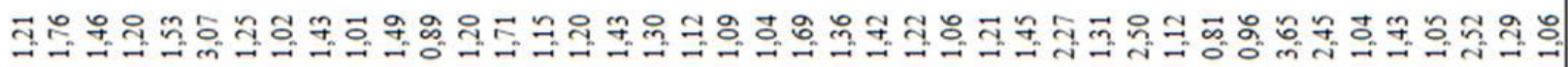

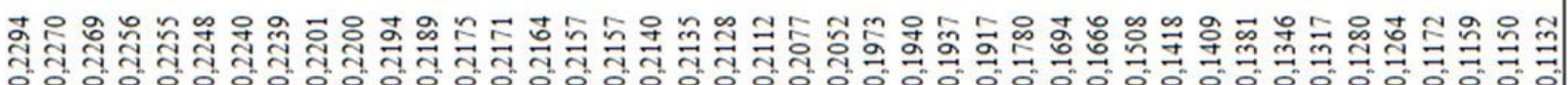

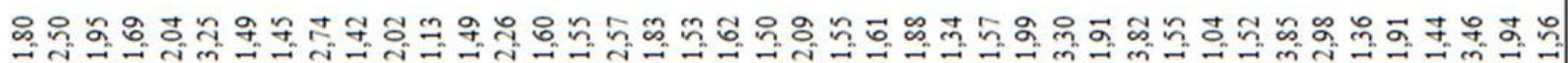

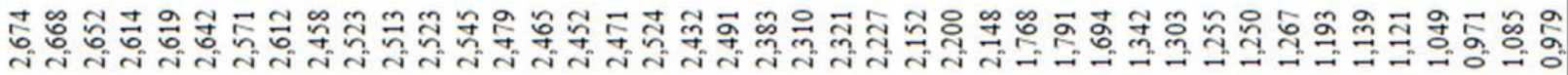

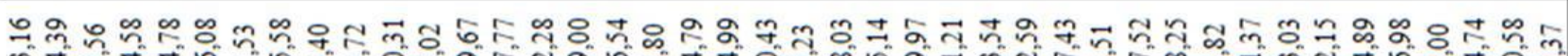

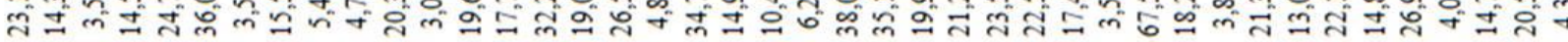

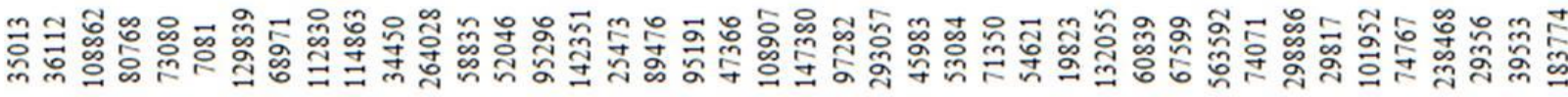

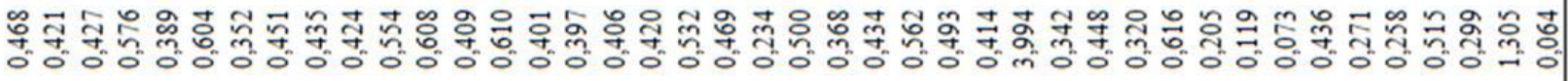

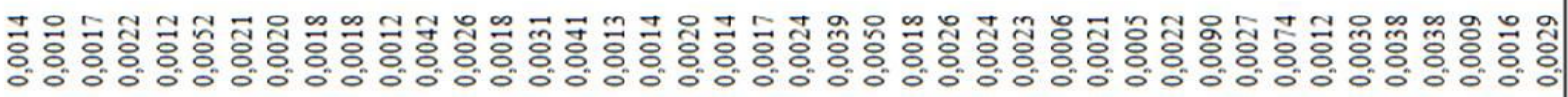

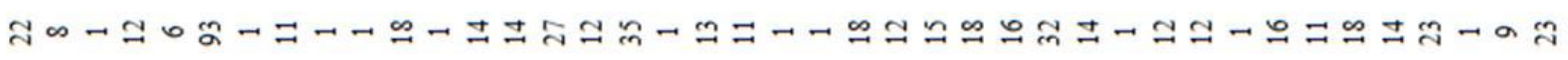

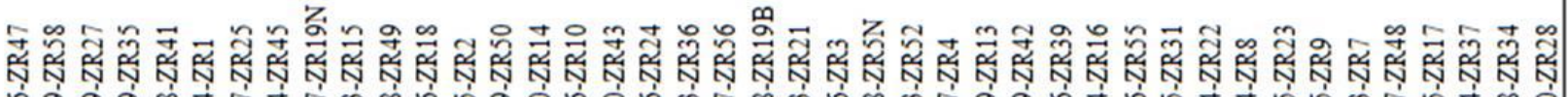

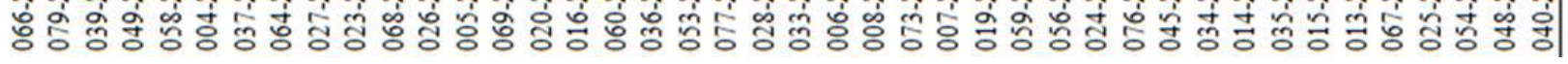

